ANL-6294

ANL-6294

Argonne Rational Laboratom

DIFFUSION-CONTROLLED DISSOLUTION OF

ZIRCONIUM IN MOLTEN URANIUM WITH

MONOTONICALLY INCREASING TEMPERATURE

by

Gerald H. Golden 


\section{DISCLAIMER}

This report was prepared as an account of work sponsored by an agency of the United States Government. Neither the United States Government nor any agency Thereof, nor any of their employees, makes any warranty, express or implied, or assumes any legal liability or responsibility for the accuracy, completeness, or usefulness of any information, apparatus, product, or process disclosed, or represents that its use would not infringe privately owned rights. Reference herein to any specific commercial product, process, or service by trade name, trademark, manufacturer, or otherwise does not necessarily constitute or imply its endorsement, recommendation, or favoring by the United States Government or any agency thereof. The views and opinions of authors expressed herein do not necessarily state or reflect those of the United States Government or any agency thereof. 


\section{DISCLAIMER}

Portions of this document may be illegible in electronic image products. Images are produced from the best available original document. 


\section{LEGAL NOTICE}

This report was prepared as an account of Government sponsored work. Neither the United States, nor the Commission, nor any person acting on behalf of the Commission:

A. Makes any warranty or representation, expressed or implied, with respect to the accuracy, completeness, or usefulness of the information contained in this report, or that the use of any information, apparatus, method, or process disclosed in this report may not infringe privately owned rights; or

B. Assumes any liabilities with respect to the use of, or for damages resulting from the use of any information, apparatus, method, or process disclosed in this report.

As used in the above, "person acting on behalf of the Commission" includes any employee or contractor of the Commission, or employee of such contractor, to the extent that such employee or contractor of the Commission, or employee of such contractor prepares, disseminates, or provides access to, any information pursuant to his employment or contract with the Commission, or his employment with such contractor.

Price $\$ 1.00$. Available from the Office of Technical Services, Department of Commerce, Washington 25, D.C. 
ANL- 6294

Chemistry

(TID-4500, I 6th Ed.)

AEC Research and

Development Report

\section{ARGONNE NATIONAL LABORATORY \\ 9700 South Cass Avenue \\ Argonne, Illinois}

\section{DIFFUSION - CONTROLLED DISSOLUTION OF \\ ZIRCONIUM IN MOLTEN URANIUM WITH \\ MONOTONICALLY INCREASING TEMPERATURE}

by

Gerald H. Golden

Reactor Engineering Division

January 1961

Operated by The University of Chicago

under

Contract W-31-109-eng-38 
TABLE OF CONTENTS

Page

ABSTRACT .......................... 4

NOMENCLATURE .................... 4

I. INTRODUCTION. .................... 7

A. Background......................... 7

B. Scope of the Present Study.................. 9

II. EQUATIONS FOR DIFFUSION-CONTROLLED DISSOLUTION . . 10

A. Basic Assumptions in Selecting Mode1 ........... 10

B. Description of the Dissolution Model ............ 13

C. Derivation of Dissolution Equations............ 14

III. APPLICATIONS OF DISSOLUTION EQUATIONS. . . . . . . . 20

A. Case of Constant Reactor Power.............. 20

B. Case of Exponentially Increasing Reactor Power . . . . . . 24

C. Case of Linearly Increasing Reactor Power . . . . . . . . 28

D. Discussions of Observed Linearity of $\mathrm{k}$ with $\tau \ldots \ldots . \ldots 32$

IV. CONCLUSIONS. .................... 34

APPENDIX A. DERIVATION OF ONE-DIMENSIONAL RECTANGULAR FINITE GEOMETRY, CONSTANT-TEMPERATURE, DIFFUSION-CONTROLLED DISSOLUTION EQUATION . . . . 37

APPENDIX B。DERIVATION OF ONE-DIMENSIONAL CYLINDRICAL FINITE GEOMETRY, CONSTANT -TEMPERATURE, DIFFUSION-CONTROLLED DISSOLUTION EQUATION . . . . . 40

APPENDIX C。 ESTIMATION OF $D_{0}$ AND $\epsilon \ldots \ldots \ldots . \ldots \ldots 42$

BIBLIOGRAPHY. ..................... 43

ACKNOWLEDGMENT . . . . . . . . . . . . . . . . . 43 
LIST OF TABLES

No.

Title

$\underline{\text { Page }}$

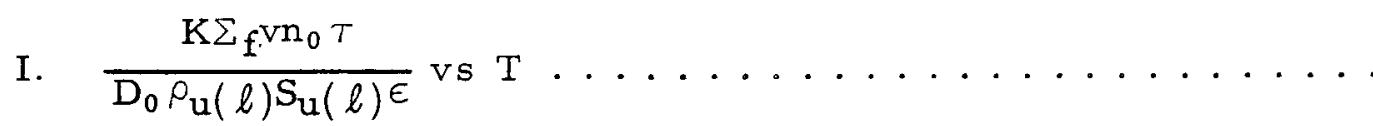

II. $T$ vs $\mathrm{T}$ for $\mathrm{dT} / \mathrm{dt}=3,676{ }^{\circ} \mathrm{K} / \mathrm{sec} \ldots \ldots 21$

III. $\mathrm{k}$ vs $\tau$ for $\mathrm{dT} / \mathrm{dt}=3,676 \mathrm{~K} / \mathrm{sec} \ldots \ldots 22$

IV. Interface Recession for $\mathrm{dT} / \mathrm{dt}=3,676^{\circ} \mathrm{K} / \mathrm{sec} \ldots \ldots 23$

V. Interface Recession for $\mathrm{dT} / \mathrm{dt}=367.6^{\circ} \mathrm{K} / \mathrm{sec} \ldots \ldots 24$

VI. $\quad \tau$ vs $\mathrm{T}$ for $\mathrm{dT} / \mathrm{dt}=20.0(\mathrm{~T}+319) \mathrm{K} / \mathrm{sec} \ldots \ldots 26$

VII. $\mathrm{k}$ vs $T$ for $\mathrm{dT} / \mathrm{dt}=20.0(\mathrm{~T}+319){ }^{\circ} \mathrm{K} / \mathrm{sec} \ldots \ldots 26$

VIII. Interface Recession for $\mathrm{dT} / \mathrm{dt}=20.0(\mathrm{~T}+319)^{\circ} \mathrm{K} / \mathrm{sec} \ldots . .27$

IX. Interface Recession for $\mathrm{dT} / \mathrm{dt}=0.10(\mathrm{~T}+319)^{\circ} \mathrm{K} / \mathrm{sec} \ldots 28$

X. $\quad \tau$ vs $\mathrm{T}$ for $\mathrm{dT} / \mathrm{dt}=27.12 \sqrt{\mathrm{T}+319}{ }^{\circ} \mathrm{K} / \mathrm{sec} \ldots \ldots 30$

XI. $\quad \mathrm{k}$ vs $T$ for $\mathrm{dT} / \mathrm{dt}=27.12 \sqrt{\mathrm{T}+319} \mathrm{~K} / \mathrm{sec} \ldots \ldots 30$

XII. Interface Recession for $\mathrm{dT} / \mathrm{dt}=27.12 \sqrt{\mathrm{T}+319}{ }^{\circ} \mathrm{K} / \mathrm{sec} \ldots \quad 31$

XIII. Interface Recession for $\mathrm{dT} / \mathrm{dt}=8.576 \sqrt{\mathrm{T}+319}{ }^{\circ} \mathrm{K} / \mathrm{sec} \ldots . \quad 31$

XIV. Computation of $\frac{1}{\zeta} \frac{\mathrm{dk}}{\mathrm{d} \tau}$ vs $\mathrm{T} \ldots \ldots \ldots 33$

\section{LIST OF FIGURES}

No.

Title

Page

l Heat Content of Natural Uranium. ............. 12

$2 \quad \mathrm{k} v s \mathrm{t}$ for $\mathrm{dT} / \mathrm{dt}=3,676 \mathrm{~K} / \mathrm{sec} \ldots \ldots \ldots$

$3 \quad \mathrm{k} v \mathrm{vs}$ for $\mathrm{dT} / \mathrm{dt}=20.0(\mathrm{~T}+319){ }^{\circ} \mathrm{K} / \mathrm{sec} \ldots \ldots 27$

$4 \quad \mathrm{k} v \mathrm{vs}$ for $\mathrm{dT} / \mathrm{dt}=27.12 \sqrt{\mathrm{T}+319} \mathrm{~K} / \mathrm{sec} \ldots 30$ 


\title{
DIFFUSION-CONTROLLED DISSOLUTION OF ZIRCONIUM IN MOLTEN URANIUM WITH MONOTONICALLY INC REASING TEMPERATURE
}

by

Gerald H. Golden

\begin{abstract}
The diffusion-controlled dissolution of zirconium in molten uranium was studied for the case in which the temperature increased monotonically with time. A physical model for diffusion-controlled dissolution was postulated, and the equations solved for the specific cases in which the temperature increased linearly, exponentially and parabolically with time. In order to solve these equations it was found useful to transform time as an independent variable to a parameter $\tau$ which takes into account the variation with time of the temperature and diffusion coefficient.
\end{abstract}

For the range of parameters considered to be of experimental interest, the recession of the solid-liquid interface as a function of $\tau$ was approximately given by the same expression for all three cases of temperature variation:

$$
\Delta \mathrm{L}=2\left(\frac{T}{\pi}\right)^{\frac{1}{2}}\left[\mathrm{~b}+\frac{2}{3} \mathrm{aT}\right]
$$

Here $\Delta \mathrm{L}$ is the interface recession, and a and b are constants determined from the conditions of the specific case being studied.

The dis solution equations developed in this study may well be applied to the investigation of the diffusion-controlled dissolution of certain other metals in molten uranium.

NOMENCLATURE

$$
\begin{aligned}
\mathrm{t}= & \text { time, } \mathrm{sec} \\
\mathrm{c}(\mathrm{x}, \mathrm{t})= & \text { concentration of zirconium in molten uranium at point } \mathrm{x} \\
& \text { at time } \mathrm{t}, \mathrm{gm} / \mathrm{cm}^{3} \\
\mathrm{~T}(\mathrm{t})= & \text { average system temperature at time } t,{ }^{\circ} \mathrm{K}
\end{aligned}
$$


$\mathrm{T}_{\mathrm{d}}=$ datum temperature, taken to be $298^{\circ} \mathrm{K}$

$\mathrm{T}_{0}=$ natural uranium melting point, $1406^{\circ} \mathrm{K}$

$\mathrm{D}[\mathrm{T}(\mathrm{t})]=$ diffusion coefficient as function of temperature, $\mathrm{cm}^{2} / \mathrm{sec}$

$D_{0}=$ amplitude term in equation for diffusion coefficient (see Equation II. 1) $\mathrm{cm}^{2} / \mathrm{sec}$

$E=$ activation energy for diffusion process, cal $/ \mathrm{mole}$

$\mathrm{R}=$ gas constant, $1.987 \mathrm{cal} / \mathrm{mole}{ }^{\circ} \mathrm{K}$

$\epsilon=\mathrm{E} / \mathrm{R},{ }^{\circ} \mathrm{K}$

$n(t)=$ average neutron density in system as function of time, neutron $/ \mathrm{cm}^{3}$

$\mathrm{K}=$ conversion factor, $6.318 \times 10^{-12}$ calorie absorbed in uranium/fission

$\Sigma_{\mathrm{f}}=$ macroscopic cross section for thermal fission of natural uranium, $0.1788 \mathrm{~cm}^{-1}$

$\mathrm{v}=$ average thermal neutron velocity, $2.20 \times 10^{5} \mathrm{~cm} / \mathrm{sec}$

$\rho_{\mathrm{Zr}}=$ density of zirconium, as sumed constant at $6.49 \mathrm{gm} / \mathrm{cm}^{3}$

$\rho_{\mathrm{U}}=$ density of uranium, $\mathrm{gm} / \mathrm{cm}^{3}$

$\mathrm{S}_{\mathrm{U}}=$ specific heat of uranium $\mathrm{cal} / \mathrm{gm}^{\circ} \mathrm{K}$

$k[T(t)]=$ ratio of equilibrium concentration of zirconium in molten uranium at temperature $\mathrm{T}$ to density of solid zirconium at the same temperature, $\left(\mathrm{gm} / \mathrm{cm}^{3}\right) /\left(\mathrm{gm} / \mathrm{cm}^{3}\right)$

$L=$ distance from center of system to solid-liquid interface, $\mathrm{cm}$

$\tau=$ variable defined by Equation (II.14), $\mathrm{cm}^{2}$

$\mathrm{a}, \mathrm{b}=$ parameters defined by Equation (II.19)

erf $x=(2 / \sqrt{\pi}) \int_{0}^{x} e^{-\lambda^{2}} d \lambda$, error function, dimensionless

erfc $x=(2 / \sqrt{\pi}) \int_{x}^{\infty} e^{-\lambda^{2}} d \lambda$, complimentary error function, dimensionless

$\mathrm{w}(\tau)=$ mass of zirconium in solution at $\tau, \mathrm{gm} / \mathrm{cm}^{2}$ normal to direction of diffusion

$\lambda=1 / \theta$, where $\theta$ is the reactor period, assumed constant 


\section{INTRODUCTION}

\section{A. Background}

An extensive program at Argonne National Laboratory undertakes to demonstrate the feasibility of fast reactors as economically competitive sources of power. Since by their nature such reactors contain large amounts of fissile material, considerable attention is being given to the complex problem of fast reactor safety. (1) One phase of this problem is concerned with the possible modes of reassembly of a fast reactor core that undergoes partial or total meltdown as a result of a reactor accident. In order to predict these modes of reassembly it is desirable to have some insight into the mechanism of failure of individual fuel elements.

If a fuel element consists of an alloy containing fissile material, surrounded by a refractory metal cladding, then failure of the element occurs when molten alloy penetrates the cladding. Such failure may be due to one or a combination of the following factors:

1. progressive interaction of the alloy with the cladding,

2. heating of the cladding to its melting point before significant interaction with the alloy can occur,

3. the generation of excess pressure inside the element by gas, and

4. cracking of the cladding due to thermal stresses.

Failure by the first of the above factors is considered in this report. Failure by the second factor can occur as a special case of the first if the system temperature attains the cladding melting point before the alloy interacts completely with the cladding. This effect is also treated in this report.

The diffusion-controlled dissolution of zirconium into molten uranium at constant temperature was considered in an earlier report. (2) The zirconium-uranium system was selected for study because some solubility data are available and also because the liquid solution appears to be nearly ideal over the entire range of solubility of zirconium in molten uranium. (3) The following three cases were investigated, employing the one-dimensional, rectangular form of the diffusion equation:

1. the solid-liquid interface is stationary, and the liquid is infinitely deep;

2. the solid-liquid interface is stationary, but the liquid has a finite depth;

3. the solid-liquid interface moves with time, and the liquid is infinitely deep. 
Equations were derived for the concentration of zirconium in molten uranium as a function of position and time, and for the position of the solidliquid interface as a function of time.

The primary value of the earlier study is that it suggests the design of experiments for determining the diffusion coefficient as a function of temperature, employing either the concentration equations or interface movement equations.

The study also may be used to give a measure of the error resulting from the use of nonexact physical models in deriving the expressions for the concentration and interface movement. As an example of this latter point, assume that it is desired to predict the time required for molten uranium at $1543^{\circ} \mathrm{K}$ to penetrate a cylindrical annulus of zirconium cladding. Let the inside radius of the cladding, $r$, be $0.400 \mathrm{~cm}$ and let the thickness of the cladding be $0.0200 \mathrm{~cm}$.

The simplest model to use in making the prediction is a stationary interface, one-dimensional rectangular geometry in which zirconium dissolves into molten uranium of semi-infinite extent, corresponding to case 1 above. For this case, (2)

$$
\Delta \mathrm{r}=2 \mathrm{k}(\mathrm{T}) \sqrt{\mathrm{Dt} / \pi} \text {. }
$$

At $1543^{\circ} \mathrm{K},(8)$

$$
\begin{aligned}
k(T) & =0.130 ; \\
D & =1.90 \times 10^{-4} \mathrm{~cm}^{2} / \mathrm{sec} \quad .
\end{aligned}
$$

Thus,

$$
0.0200=2 \times 0.130 \times \sqrt{1.90 \times 10^{-4} \mathrm{t} / \pi}
$$

or

$$
\mathrm{t}=97.8 \mathrm{sec} \quad .
$$

An improvement on the above result is obtained if the one-dimensional, rectangular, semi-infinite geometry is replaced by a one-dimensional, rectangular, finite geometry. This corresponds to case 2 above. Set $r / 2 \sqrt{D} t=\alpha$. Then it can be shown (see Appendix A) that

$$
\begin{aligned}
\frac{\alpha}{\mathrm{k}(\mathrm{T})} \frac{\Delta \mathrm{r}}{\mathrm{r}}= & \sum_{\mathrm{n}=0}^{\infty}(-1)^{\mathrm{n}}\left\{2 \alpha+[2 \mathrm{n} \alpha] \operatorname{erf}[2 \mathrm{n} \alpha]+\frac{1}{\sqrt{\pi}}\left(\mathrm{e}^{-[2 \mathrm{Ln} \alpha]^{2}}-\mathrm{e}^{-[2(\mathrm{n}+1) \alpha]^{2}}\right)\right. \\
& -[2(\mathrm{n}+1) \alpha] \operatorname{erf}[2(\mathrm{n}+1) \alpha]\} .
\end{aligned}
$$


Employing the given values of $r, \Delta r, k(T)$ and $D$, the above equation may be solved for $t$ by trial and error, giving

$$
t=97.9 \mathrm{sec} \quad .
$$

A further improvement is obtained if the one-dimensional, cylindrical, finite geometry is used. It can be shown for this case (see Appendix B) that

$$
\frac{\Delta r}{r}=k(T)\left[\frac{1}{2}-\frac{2}{r^{2}} \sum_{n=1}^{\infty} \frac{1}{\beta_{n}^{2}} e^{-D \beta_{n}^{2} t}\right] \text {, }
$$

where the $\beta_{n}$ are the roots of

$$
\mathrm{J}_{0}\left(\mathbf{r} \beta_{\mathrm{n}}\right)=0
$$

Employing the given values of $r, \Delta r, k(T)$ and $D$, the above equations are solved to give

$$
t=160 \mathrm{sec}
$$

The reason that the dissolution time predicted by the finite cylindrical geometry is greater, by a factor of almost two, than that predicted by the rectangular finite geometry is discussed in the conclusion of this report.

\section{B. Scope of the Present Study}

While the previous study is useful in the design and interpretation of experiments for determining the diffusion coefficient of zirconium in molten uranium at constant temperature, it is not readily applicable to the study of diffusion-controlled dissolution under conditions of variable solution temperature. It might at first seem possible to approximate closely a variable-temperature system by a large number of constant-temperature systems, solutions for which were obtained in the earlier study. However, in obtaining those solutions it was assumed that the initial concentration of zirconium in the molten uranium was zero. If a large number of constanttemperature systems are used as a finite difference approximation, then the condition of zero initial concentration is true only for the very first constant-temperature approximation. From then on the initial concentration to be employed in each constant-temperature approximation becomes a function of position and time, and hence the constant-temperature equations as originally derived cannot be applied to the problem of a variable temperature.

The purposes of the present study are to propose a physical model for the diffusion-controlled dissolution of zirconium in molten uranium under conditions of monotonically increasing uranium temperature, and 
then to solve the appropriate equations. The physical model selected was a compromise between the desire to represent as closely as possible the actual dissolution and the ability to obtain analytical solutions of the equations.

Specifically, the model chosen is one in which the movement of the solid-liquid interface with time is negligible, and in which diffusion is described by the one-dimensional, rectangular form of the diffusion equation. The average system temperature is determined from a heat balance, i.e., the rate of increase of the uranium temperature is taken to be proportional to the fission-rate of the included $\mathrm{U}^{235}$, neglecting heat leakage from the system. Equations were derived for the recession of the solid-liquid interface for the following three cases of variation of fission rate with time:

1. constant,

2. exponential, and

3. linear.

These equations were solved for specific systems in which the variation of fission rate with time might approximate that obtainable in, say, the Transient Reactor Test Facility at the National Reactor Testing Station.

\section{EQUATIONS FOR DIFFUSION-CONTROLLED DISSOLUTION}

\section{A. Basic Assumptions in Selecting Model}

The most basic assumption that has been made in selecting a model for the dissolution of zirconium into molten uranium is that the rate of dissolution is purely diffusion controlled over the entire range of dissolution temperature. However, as has been pointed out elsewhere, (2) at temperatures nearer to the zirconium melting point than the uranium melting point the dissolution rate may become solute phase-transfer controlled rather than diffusion controlled. Experimentation is required to show at what temperature, if ever, the solute phase-transfer mechanism becomes significant for this system. Until such experiments are carried out, the basic assumption of diffusion control appears to be reasonable.

Since no experimental work has been done on the concentration dependence of the diffusion coefficient of zirconium in molten uranium, it is assumed in this work that the diffusion coefficient is independent of concentration. The temperature dependence of the diffusion coefficient for this system is assumed to follow the Arrhenius equation:

$$
D[T(t)]=D_{0} e^{-E / R T(t)}=D_{0} e^{-\epsilon / T(t)} .
$$


The Arrhenius form of the diffusion coefficient variation with temperature is supported by considerable experimental evidence. (4)

The variation of the average system temperature with time, $T(t)$, may be obtained from a heat balance. The rate of heat generation in unit volume of natural uranium is directly proportional to the fission rate, i.e., to the neutron density in the volume. In any interval of temperature in which a change of phase does not occur,

$$
\rho_{\mathrm{U}^{S}} \mathrm{~S}_{\mathrm{UT}}=\mathrm{K} \Sigma_{\mathrm{f}} \mathrm{nvdt}
$$

or

$$
\frac{d T}{d t}=\frac{K \Sigma_{f} n V}{\rho_{U} S_{U}}
$$

An examination of Fig. 1 shows that in the liquid phase the specific heat of natural uranium $(10)$ is essentially constant [at $\left.9.20 \mathrm{cal} /(\mathrm{mole})\left({ }^{\circ} \mathrm{K}\right)\right]$. It is useful here to assign a fictitious mean specific heat, $\overline{\mathbf{S}}_{U}$, to the solid phase that takes into account the $\alpha-\beta, \beta-\gamma$, and $\gamma$-liquid heats of transition. The heat content corresponding to this fictitious mean specific heat is shown by the dotted line in Fig. 1. It does not correspond to the true temperature of the solid, but this is of no importance in the present study (solid-phase diffusion is negligibly small compared to liquid-phase diffusion). It does, however, give correctly the heat content of the uranium at the instant it just completely liquefies. The value of $\bar{S}_{U}$ is computed to be $13.547 \mathrm{cal} /(\mathrm{mole})\left({ }^{\circ} \mathrm{K}\right)$. With the uranium melting point denoted by $\mathrm{T}_{0}$ and the liquid phase by the subscript $l$, the heat balance is given by the equations

$$
\begin{aligned}
& \mathrm{T}_{0}-\mathrm{T}_{\mathrm{d}}=\frac{\mathrm{K} \Sigma_{\mathrm{f}} \mathrm{v}}{\bar{\rho}_{\mathrm{U}} \overline{\mathrm{S}}_{\mathrm{U}}} \int_{0}^{\mathrm{t}_{0}} \mathrm{n}\left(\mathrm{t}^{\prime}\right) \mathrm{dt^{ \prime }} ; \mathrm{T}_{0} \geq \mathrm{T} \geq \mathrm{T}_{\mathrm{d}}, \mathrm{t}_{0} \geq \mathrm{t} \geq 0 ; \\
& \mathrm{T}(\mathrm{t})-\mathrm{T}_{0}=\frac{\mathrm{K} \Sigma_{\mathrm{f}} \mathrm{v}}{\rho_{\mathrm{U}(\ell)} \mathrm{S}_{\mathrm{U}(\ell)}} \int_{\mathrm{t}_{0}}^{\mathrm{t}} \mathrm{n}\left(\mathrm{t}^{\prime}\right) \mathrm{dt^{ \prime }} ; \mathrm{T} \geq \mathrm{T}_{0}, \mathrm{t} \geq \mathrm{t}_{0}
\end{aligned}
$$

For a given form of $n(t)$, Equation (II.2) can be solved for $t_{0}$, the time at which the uranium has just completely liquefied. Then with this value of $t_{0}$, Equation (II. $2^{\prime}$ ) gives $T$ as a function of $t$. 


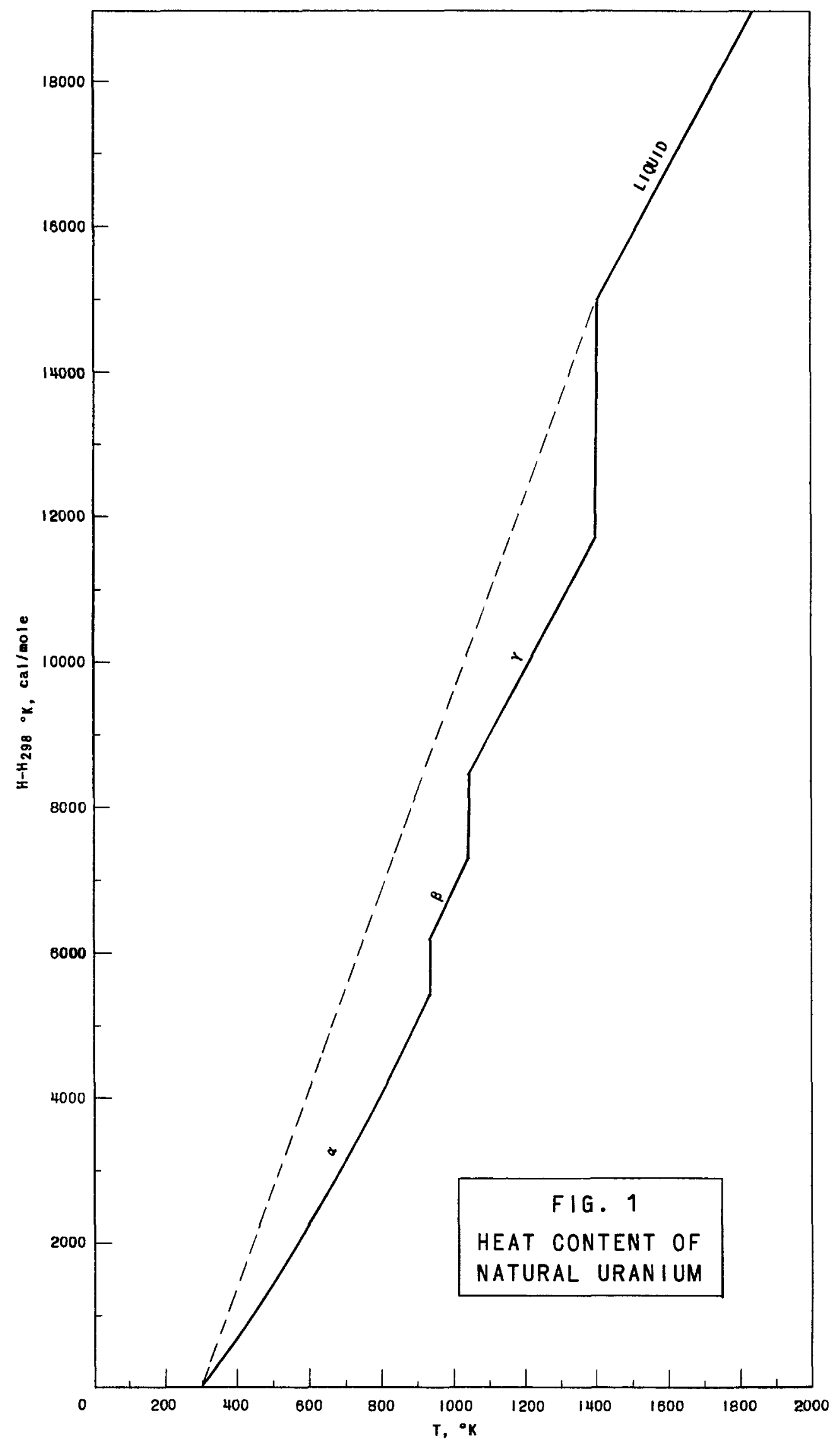


B. Description of the Dissolution Model

In specifying the dissolution model to be studied, it was assumed that the position of the solid zirconium-molten uranium interface does not vary with time (the reason this is necessary is brought forth later in the discussion). Physically, this assumption is equivalent to one by which the zirconium dissolves into the molten uranium with no increase in volume of the solution, and hence it appears to be reasonable for zirconium thicknesses very much smaller than the uranium thickness. The dissolution model is cast in a one-dimensional, rectangular geometry, but at the cost of considerably complicating the calculations, the techniques of solution developed may be applied to a model in a cylindrical geometry.

The dissolution model is shown below:

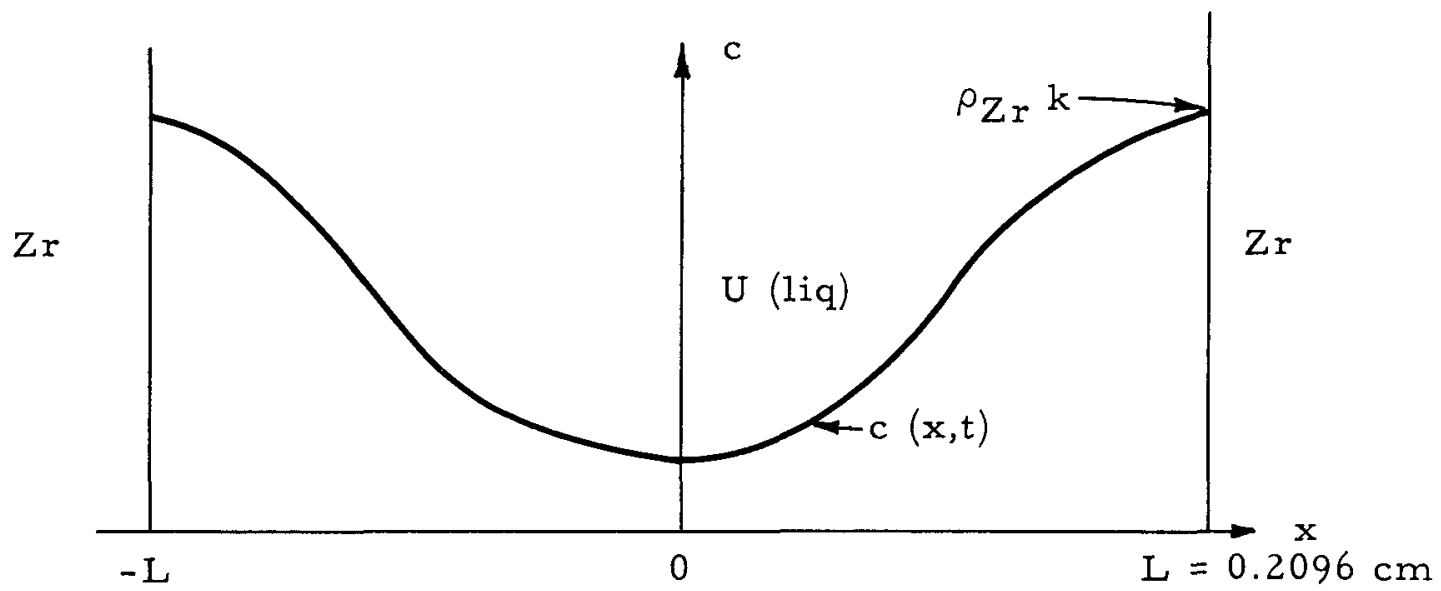

Here $L$ is taken to be $0.2096 \mathrm{~cm}$, because this is the arithmetic mean radius of the cladding in the EBR-II fuel pin, and as such represents a realistic value of $L$.

The equations describing this model are:

$$
\begin{aligned}
& \frac{\partial c}{\partial t}=D[T(t)] \frac{\partial^{2} c}{\partial x^{2}} ;-L<x<L, t \geq t_{0} ; \\
& c\left(x, t_{0}\right)=0 ;-L<x<L ; \\
& c( \pm L, t)=\rho_{Z r} k[T(t)] ; t \geq t_{0} ; \\
& \left.\frac{\partial c}{\partial x}\right|_{x=0}=0, t \geq t_{0}
\end{aligned}
$$


Equation (II.3) is a statement of the one-dimensional rectangular form of the diffusion equation. Equation (II.4) is the initial condition that the concentration of zirconium in the uranium at time $t_{0}$, when the uranium has just completely melted, is zero everywhere except at the solid-liquid interface. Equation (II.5) asserts that the concentration of zirconium in the solution at the interface is always equal to the equilibrium concentration at the given solution temperature. Here $k[T]$ is the ratio of the equilibrium concentration of zirconium in molten uranium at temperature $\mathrm{T}$ to the density of solid zirconium at temperature $T$, and may be computed from equilibrium solubility data for the uranium-zirconium system. (2) If the parameter L in Equation (II.5) is made time-dependent, then the system of Equations (II.3)-(II.6) cannot be solved either by the method of separation of variables or the Laplace transform. It is for this reason that it is necessary to assume that $L$ is constant (it is incorrect to assume here that $\Delta \mathrm{L} \propto \sqrt{\mathrm{t}} ; \mathrm{such}$ an assumption holds only for a constant temperature system). Equation (II.6) states that because of the symmetry of the model, there is no net flow of solute across the plane $\mathbf{x}=0$.

\section{Derivation of Dissolution Equations}

Two successive changes of variable and an approximating assumption were employed to transform the system of Equations (II.3)-(II.6) to a system that is readily solved by means of the Laplace transform. The desirability of obtaining such a solution is due to its anticipated form; it is expected to give the concentration of zirconium in molten uranium as an infinite series whose terms contain error functions and negative exponentials. Such a series is characterized by rapid convergence, which is convenient for purposes of numerical computation.

First, time as an independent variable is eliminated by noting that

$$
\frac{\partial c}{\partial t}=\frac{\partial c}{\partial T} \frac{d T}{d t}
$$

Thus, for $\mathrm{T} \geq \mathrm{T}_{0}$,

$$
\begin{aligned}
& \frac{\partial c}{\partial t}=\frac{D_{0} e^{-\epsilon / T}}{d T / d t} \frac{\partial^{2} c}{\partial x^{2}} \\
& c\left(x, T_{0}\right)=0 \\
& c( \pm L, T)=\rho_{Z r} k[T] \\
& \left.\frac{\partial c}{\partial x}\right|_{x=0}=0
\end{aligned}
$$


where $\mathrm{T}_{0}=1406^{\circ} \mathrm{K}$, the melting point of uranium. Assuming that $\mathrm{dT} / \mathrm{dt}$ can be expressed as a function of $\mathrm{T}$, set

$$
\frac{D_{0} e^{-\epsilon / T}}{d T / d t} \equiv F(T)
$$

Because of the presence of $F(T)$ in Equation (II.8) the Laplace trans form of that equation is not readily obtainable. Hence, as the second change of variable, set

$$
\mathrm{d} T=F(T) \mathrm{d} T
$$

whose integrated form is

$$
\tau=\int_{\mathrm{T}_{0}}^{\mathrm{T}} F\left(\mathrm{~T}^{\prime}\right) \mathrm{d}^{\prime}
$$

Then the system of Equations (II.8)-(II.11) becomes

$$
\begin{aligned}
& \frac{\partial c}{\partial \tau}=\frac{\partial^{2} c}{\partial x^{2}} ; \\
& c(x, 0)=0 ; \\
& c(t L, \tau)=\rho Z_{x} k[T(t)] ; \\
& \left.\frac{\partial c}{\partial x}\right|_{x=0}=0 ;
\end{aligned}
$$

In order to obtain an analytical expression for the Laplace transform of Equation (II.17), it is necessary to have an analytical expression for $k[T(\tau)]$. It is shown in the following section, for at least the three cases below,

1. linearly increasing molten uranium temperature, corresponding to constant reactor power;

2. exponentially increasing molten uranium temperature, corresponding to exponentially increasing reactor power;

3. parabolically increasing molten uranium temperature, corresponding to linearly increasing reactor power;

at values of $\tau$ corresponding to the higher values of $T$, that $k$ is linear in $\tau$ for the range of parameters considered, i.e.,

$$
\mathrm{k}[\mathrm{T}(\tau)]=\mathrm{a} \tau+\mathrm{b} .
$$


The system of Equations (II.15)-(II.18) is now solved. Define the Laplace transform of $\mathrm{c}(\mathrm{x}, \tau)$ as

$$
L\{c(x, \tau)\}=\int_{0}^{\infty} c(x, \tau) e^{-P T} d \tau=\bar{c}(x, P)
$$

Transforming Equation (II.15) and simplifying by means of Equation(II.16),

$$
P \bar{c}(x, P)=\frac{\partial^{2} \bar{c}(x, P)}{\partial x^{2}},
$$

or

$$
\bar{c}(x, P)=A e^{-x \sqrt{P}}+B e^{x} \sqrt{P} \quad ;
$$

hence,

$$
\frac{\partial \bar{c}}{\partial x}=-A \sqrt{P} e^{-x \sqrt{P}}+B \sqrt{P} e^{x \sqrt{P}} .
$$

Transforming Equation (II.18),

$$
\left.\frac{\partial \bar{c}}{\partial x}\right|_{x=0}=0 ; \sqrt{P} \neq 0 \Rightarrow A=B
$$

Thus Equation (II.21) becomes:

$$
\bar{c}(x, P)=A\left(e^{-x \sqrt{P}}+e^{x \sqrt{P}}\right) \quad .
$$

Combining Equations (II.17) and (II.19),

$$
c( \pm L, T)=\rho_{Z_{r}}(a r+b),
$$

and transformation of this result gives

$$
\bar{c}( \pm L, P)=\rho_{Z r}\left(\frac{a}{P^{2}}+\frac{b}{P}\right)
$$

Combining Equations (II.22) and (II.24) and solving for A,

$$
A=\frac{\rho_{Z_{r}}}{e^{-L \sqrt{P}}+e^{L \sqrt{P}}}\left(\frac{a}{P^{2}}+\frac{b}{P}\right)
$$

Substituting this value of A into Equation (II.22) and rearranging,

$$
\bar{c}(x, P)=\rho_{Z r}\left(\frac{a}{P^{2}}+\frac{b}{P}\right) \frac{e^{-(L+x) \sqrt{P}+e^{-(L-x) \sqrt{P}}}}{1+e^{-2 L} \sqrt{P}} .
$$


The denominator of the right side of Equation (II.25) is expanded by means of the binomial theorem:

$$
\left(1+e^{-2 L} \sqrt{P}\right)^{-1}=\sum_{n=0}^{\infty}(-1)^{n} e^{-2 n L} \sqrt{P}
$$

Substituting this result back into Equation (II.25) and rearranging,

$$
\begin{aligned}
\bar{c}(x, P)= & \frac{\rho_{Z_{r} b}}{P} \sum_{n=0}^{\infty}(-1)^{n}\left[e^{-[(2 n+1) L+x] \sqrt{P}}+e^{-[(2 n+1) L-x] \sqrt{P}}\right] \\
& +\frac{\rho_{Z_{r}} a}{P^{2}} \sum_{n=0}^{\infty}(-1)^{n}\left[e^{-[(2 n+1) L+x] \sqrt{P}}+e^{-[(2 n+1) L-x] \sqrt{P}}\right] .
\end{aligned}
$$

The inverse transform of Equation (II.26) is evaluated from a tabulation in the literature: $(5)$

$$
\begin{aligned}
c(x, \tau)= & \rho_{Z} \mathbf{b} \sum_{n=0}^{\infty}(-1)^{n}\left[\operatorname{erfc} \frac{(2 n+1) L+x}{2 \sqrt{\tau}}+\operatorname{erfc} \frac{(2 n+1) L-x}{2 \sqrt{\tau}}\right] \\
& +\rho_{Z_{r}} a \sum_{n=0}^{\infty}(-1)^{n}\left\{\left(\tau+\frac{[(2 n+1) L+x]^{2}}{2}\right) \operatorname{erfc} \frac{(2 n+1) L+x}{2 \sqrt{\tau}}\right. \\
& -[(2 n+1) L+x]\left(\frac{\tau}{\pi}\right)^{\frac{1}{2}} e^{-\frac{[(2 n+1) L+x]^{2}}{4 \tau}}+\left(\tau+\frac{[(2 n+1) L-x]^{2}}{2}\right) \operatorname{erfc} \frac{(2 n+1) L-x}{2 \sqrt{T}} \\
& \left.-[(2 n+1) L-x]\left(\frac{\tau}{\pi}\right)^{\frac{1}{2}} e^{-\frac{[(2 n+1) L-x]^{2}}{4 \tau}}\right\}
\end{aligned}
$$

Substitution of $x= \pm L$ into Equation (II.27) verifies that $c( \pm L, \tau)=\rho_{Z_{r}}(a \tau+b)$, as demanded by Equation (II.23).

With the above result it becomes possible to estimate the recession of the solid-liquid interface at a given value of $\tau$. This is done by noting that the total amount of solute in the solution at a given $\tau$ is proportional to the recession of the interface. The amount of solute in solution at $\tau$, due to dissolution from the plane $\mathrm{x}=\mathrm{L}$, is

$$
\mathrm{w}(\tau)=\int_{0}^{\mathrm{L}} \mathrm{c}(\mathrm{x}, \tau) \mathrm{dx}=\rho_{\mathrm{Zr}} \Delta \mathrm{L}(\tau) \quad .
$$


Substituting Equation (II.27) into Equation (II.28), solving for $\Delta \mathrm{L}(\tau)$, and performing the indicated integrations (9) yields

$$
\begin{aligned}
\Delta L(\tau)= & 2 \sum_{n=0}^{\infty}(-1)^{n}\left\{L\left[b+a\left(\tau+\frac{(2 n+1)^{2} L^{2}}{2}+\frac{L^{2}}{6}\right)\right]\right. \\
& -L(n+1)\left[(b+a \tau)+\frac{2 a(n+1)^{2} L^{2}}{3}\right] \operatorname{erf} \frac{(n+1) L}{\sqrt{\tau}} \\
& +L n\left[(b+a \tau)+\frac{2 a n^{2} L^{2}}{3}\right] \operatorname{erf} \frac{n L}{\sqrt{\tau}} \\
& -\left(\frac{\tau}{\pi}\right)^{\frac{1}{2}}\left[b+\frac{2 a}{3}\left[(n+1)^{2} L^{2}+\tau\right]\right] e^{-\frac{(n+1)^{2} L^{2}}{\tau}} \\
& \left.+\left(\frac{\tau}{\pi}\right)^{\frac{1}{2}}\left[b+\frac{2 a}{3}\left(n^{2} L^{2}+\tau\right)\right] e^{-\frac{n^{2} L^{2}}{\tau}}\right\}
\end{aligned}
$$

An examination of Equation (II.29) shows that:

$$
\Delta L(0)=0 \quad \text {, }
$$

which is equivalent to the initial condition specified by Equation (II.16). Such an examination also shows that the term in braces in Equation (II.29) goes to zero as $\mathrm{n}$ approaches infinity, thus checking the absolute convergence of the series. 
Equation (II.29) is expanded to $\mathrm{n}=3$ in preparation for numerical computation:

$$
\begin{aligned}
& \frac{\Delta L(\tau)}{2}=\left\{L\left[(b+a \tau)+\frac{2 a L^{2}}{3}\right] \operatorname{erfc} \frac{L}{\sqrt{\tau}}-\left(\frac{T}{\pi}\right)^{\frac{1}{2}}\left[b+\frac{2 a}{3}\left(L^{2}+\tau\right)\right] e^{-\frac{L^{2}}{\tau}}\right. \\
& \left.+\left(\frac{\tau}{\pi}\right)^{\frac{1}{2}}\left[\mathrm{~b}+\frac{2 \mathrm{a} \tau}{3}\right]\right\}-\left\{\mathrm{L}\left[\mathrm{b}+\mathrm{a}\left(\tau+\frac{14}{3} \mathrm{~L}^{2}\right)\right]\right. \\
& -2 L\left[(b+a \tau)+\frac{8}{3} a L^{2}\right] \operatorname{erf} \frac{2 L}{\sqrt{\tau}}+L\left[(b+a \tau)+\frac{2 a L^{2}}{3}\right] \operatorname{erf} \frac{L}{\sqrt{T}} \\
& \left.-\left(\frac{\tau}{\pi}\right)^{\frac{1}{2}}\left[\mathrm{~b}+\frac{2 \mathrm{a}}{3}\left(4 \mathrm{~L}^{2}+\tau\right)\right] \mathrm{e}^{-\frac{4 \mathrm{~L}^{2}}{\tau}}+\left(\frac{\tau}{\pi}\right)^{\frac{1}{2}}\left[\mathrm{~b}+\frac{2 \mathrm{a}}{3}\left(\mathrm{~L}^{2}+\tau\right)\right] \mathrm{e}^{-\frac{\mathrm{L}^{2}}{\tau}}\right\} \\
& +\left\{L\left[b+a\left(\tau+\frac{38}{3} L^{2}\right)\right]-3 L\left[(b+a \tau)+6 a L^{2}\right] \operatorname{erf} \frac{3 L}{\sqrt{T}}\right. \\
& +2 L\left[(b+a \tau)+\frac{8}{3} a L^{2}\right] \operatorname{erf} \frac{2 L}{\sqrt{T}}-\left(\frac{T}{\pi}\right)^{\frac{1}{2}}\left[b+\frac{2 a}{3}\left(9 L^{2}+\tau\right)\right] e^{-\frac{9 L^{2}}{T}} \\
& \left.+\left(\frac{\tau}{\pi}\right)^{\frac{1}{2}}\left[b+\frac{2 a}{3}\left(4 L^{2}+\tau\right)\right] e^{-\frac{4 L^{2}}{\tau}}\right\}-\left\{L\left[b+a\left(\tau+\frac{74}{3} L^{2}\right)\right]\right. \\
& -4 L\left[(b+a \tau)+\frac{32}{3} a L^{2}\right] \operatorname{erf} \frac{4 L}{\sqrt{T}}+3 L\left[(b+a \tau)+6 a L^{2}\right] \operatorname{erf} \frac{3 L}{\sqrt{\tau}} \\
& \left.-\left(\frac{\tau}{\pi}\right)^{\frac{1}{2}}\left[\mathrm{~b}+\frac{2 \mathrm{a}}{3}\left(16 \mathrm{~L}^{2}+\tau\right)\right] \mathrm{e}^{-\frac{16 \mathrm{~L}^{2}}{\tau}}+\left(\frac{\tau}{\pi}\right)^{\frac{1}{2}}\left[\mathrm{~b}+\frac{2 \mathrm{a}}{3}\left(9 \mathrm{~L}^{2}+\tau\right)\right] \mathrm{e}^{-\frac{9 \mathrm{~L}^{2}}{\tau}}\right\} .
\end{aligned}
$$




\section{APPLICATIONS OF DISSOLUTION EQUATIONS}

\section{A. Case of Constant Reactor Power}

The first application of the dissolution equations is to the case in which a reactor is visualized to operate at constant power, corresponding to constant average neutron density $\mathrm{n}_{0}$. Then the average temperature in the dissolution system, as given by Equations (II.2) and (II.2'), is

$$
T(t)=\frac{K \Sigma_{f} V n_{0} t}{\rho_{U(\ell)} S_{U(\ell)}}+T_{0}-\left(T_{0}-T_{d}\right) \frac{\bar{\rho}_{U} \bar{S}_{U}}{\rho_{U(\ell)} S_{U(\ell)}} .
$$

Thus, for the case of constant reactor power, temperature increases linearly with time. Also,

$$
\frac{\mathrm{dT}}{\mathrm{dt}}=\frac{K \Sigma_{\mathrm{f}} \mathrm{vn}_{0}}{\rho_{\mathrm{U}(\ell)} \mathrm{S}_{\mathrm{U}(\ell)}}
$$

Substitution of Equation (III.2) into Equation (II.14) gives

$$
\begin{aligned}
\tau & =\frac{D_{0} \rho_{U(\ell)} S_{U(\ell)}}{K \Sigma_{f} v n_{0}} \int_{T_{0}}^{T} e^{-\epsilon / T^{\prime}} d_{T^{\prime}}=\frac{D_{0} \rho_{U(l)} S_{U}(\ell)}{K \Sigma_{f} v n_{0}} \int_{\epsilon / T}^{\epsilon / T_{0}} \frac{e^{-u}}{u^{2}} d u \\
& =\frac{D_{0} \rho_{U(\ell) S_{U}(l)} \epsilon}{K \Sigma_{\mathrm{f} v n_{0}}}\left[\frac{e^{-\epsilon / T}}{\epsilon / T}-\int_{\epsilon / T}^{\infty} \frac{e^{-u}}{u} d u-\left\{\frac{e^{-\epsilon / T_{0}}}{\epsilon / T_{0}}-\int_{\epsilon / T_{0}}^{\infty} \frac{e^{-u}}{u} d u\right\}\right]
\end{aligned}
$$

Tabulations of the exponential integral:

$$
-\operatorname{Ei}(-x)=\int_{x}^{\infty} \frac{e^{-u}}{u} d u
$$

are found in the literature. $(6,7)$ Employing these tabulations, the quantity in braces in Equation (III.3) is found to be equal to $0.8611 \times 10^{-5}$, and a table of $\frac{K \Sigma_{f} \vee n_{0} \tau}{D_{0} \rho_{U}(\ell) S_{U}(\ell)} \epsilon$ vs. T was prepared. 
Table I

$\frac{\mathrm{K} \Sigma_{f} \vee n_{0} \tau}{D_{0} \rho U(\ell) S_{U}(\ell)^{\epsilon}} \mathrm{vs} \cdot \mathrm{T}$

\begin{tabular}{|c|c|c|c|c|c|}
\hline $\mathrm{T}\left({ }^{\circ} \mathrm{K}\right)$ & $\frac{\mathrm{K} \Sigma_{\mathrm{f}} \vee n_{0} \tau}{D_{0} \rho \mathrm{U}(\ell) \mathrm{S}_{\mathrm{U}(\ell)^{\epsilon}}} \times 10^{5}$ & $\mathrm{~T}\left({ }^{\circ} \mathrm{K}\right)$ & $\frac{\mathrm{K} \Sigma_{\mathrm{f}} \vee n_{0} \tau}{D_{0} \rho \mathrm{U}(\ell) S_{U}(\ell)^{\epsilon}} \times 10^{5}$ & $\mathrm{~T}\left({ }^{\circ} \mathrm{K}\right)$ & $\frac{\mathrm{K} \Sigma_{\mathrm{f}} \vee n_{0} \tau}{\mathrm{D}_{0} \rho \mathrm{U}(\ell) \mathrm{S}_{\mathrm{U}(\ell)}} \times 10^{5}$ \\
\hline 1406 & 0 & 1673 & 2.997 & 1923 & 10.288 \\
\hline 1473 & 0.453 & 1723 & 4.014 & 1973 & 12.520 \\
\hline 1523 & 0.899 & 1773 & 5.228 & 2023 & 15.084 \\
\hline 1573 & 1.460 & 1823 & 6.660 & 2073 & 17.999 \\
\hline 1623 & 2.153 & 1873 & 8.335 & 2093 & 19.263 \\
\hline
\end{tabular}

As the first numerical computation for the constant reactor power case, let $n_{0}=1.0 \times 10^{10}$ neutrons $/ \mathrm{cm}^{3} ;$ with $\rho_{U}(\ell)=17.50 \mathrm{gm} / \mathrm{cm}^{3}$ and $\mathrm{SU}(\ell)=9.2 \mathrm{cal} /(\mathrm{mole})\left({ }^{\circ} \mathrm{K}\right)$, the value of $\mathrm{K} \Sigma_{\mathrm{fV}} / \rho_{\mathrm{U}}(\ell) \mathrm{S}_{\mathrm{U}}(\ell)$ is calculated to be $3.676 \times 10^{-7}\left({ }^{\circ} \mathrm{K}\right)\left(\mathrm{cm}^{3}\right) / \mathrm{sec}$. Then for this case

$$
\frac{\mathrm{dT}}{\mathrm{dt}}=3,676^{\circ} \mathrm{K} / \mathrm{sec} \text {. }
$$

Only one experimental value of $\mathrm{D}[\mathrm{T}]$ for the zirconium-molten uranium system is reported in the literature; (8) using this value the Langmuir-Dushman semi-empirical equation was employed to estimate the values of $D_{0}$ and $\epsilon$ (see Appendix $\left.C\right)$ :

$$
\begin{aligned}
\mathrm{D}_{0} & =0.1660 \mathrm{~cm}^{2} / \mathrm{sec} \quad ; \\
\epsilon & =10,450{ }^{\circ} \mathrm{K}
\end{aligned}
$$

These values represent a tentative estimate, however, and should be treated as such. Thus,

$$
\frac{\mathrm{D}_{0} \in \rho_{\mathrm{U}(\ell)} S_{\mathrm{U}(\ell)}}{\mathrm{K} \Sigma_{\mathrm{f}} \mathrm{vn}_{0}}=\frac{(0.1660)(10,450)}{(3,676)}=0.4719 \text {, }
$$

and Table II is used to give $\tau$ as a function of $\mathrm{T}$ :

Table II

$\tau$ vs $\mathrm{T}$ for $\mathrm{dT} / \mathrm{dt}=3,676^{\circ} \mathrm{K} / \mathrm{sec}$

\begin{tabular}{|c|c|c|c|c|c|}
\hline $\mathrm{T}\left({ }^{\circ} \mathrm{K}\right)$ & $\tau \times 10^{5}$ & $\mathrm{~T}\left({ }^{\circ} \mathrm{K}\right)$ & $\tau \times 10^{5}$ & $\mathrm{~T}\left({ }^{\circ} \mathrm{K}\right)$ & $\tau \times 10^{5}$ \\
\hline 1406 & 0 & 1673 & 1.414 & 1923 & 4.855 \\
1473 & 0.214 & 1723 & 1.894 & 1973 & 5.908 \\
1523 & 0.424 & 1773 & 2.467 & 2023 & 7.118 \\
1573 & 0.689 & 1823 & 3.143 & 2073 & 8.494 \\
1623 & 1.016 & 1873 & 3.933 & 2093 & 9.090 \\
\hline
\end{tabular}


By cross-referencing between the above and a tabulation of $k$ vs $T,(2)$ a table of $\mathrm{k}$ vs $\tau$ is obtained:

Table III

$\mathrm{k}$ vs $\tau$ for $\mathrm{dT} / \mathrm{dt}=3,676^{\circ} \mathrm{K} / \mathrm{sec}$

\begin{tabular}{|c|c|c|c|c|c|}
\hline$\tau \times 10^{5}$ & $\mathrm{k}$ & $\tau \times 10^{5}$ & $\mathrm{k}$ & $\tau \times 10^{5}$ & $\mathrm{k}$ \\
\hline 0 & 0 & 1.414 & 0.280 & 4.855 & 0.647 \\
0.214 & 0.061 & 1.894 & 0.343 & 5.908 & 0.736 \\
0.424 & 0.111 & 2.467 & 0.412 & 7.118 & 0.831 \\
0.689 & 0.163 & 3.143 & 0.486 & 8.494 & 0.942 \\
1.016 & 0.221 & 3.933 & 0.563 & 9.090 & 1.000 \\
\hline
\end{tabular}

A plot of $k$ vs $\tau$ (see Fig. 2) shows that $k$ is proportional to $\tau$ for large $\tau$.

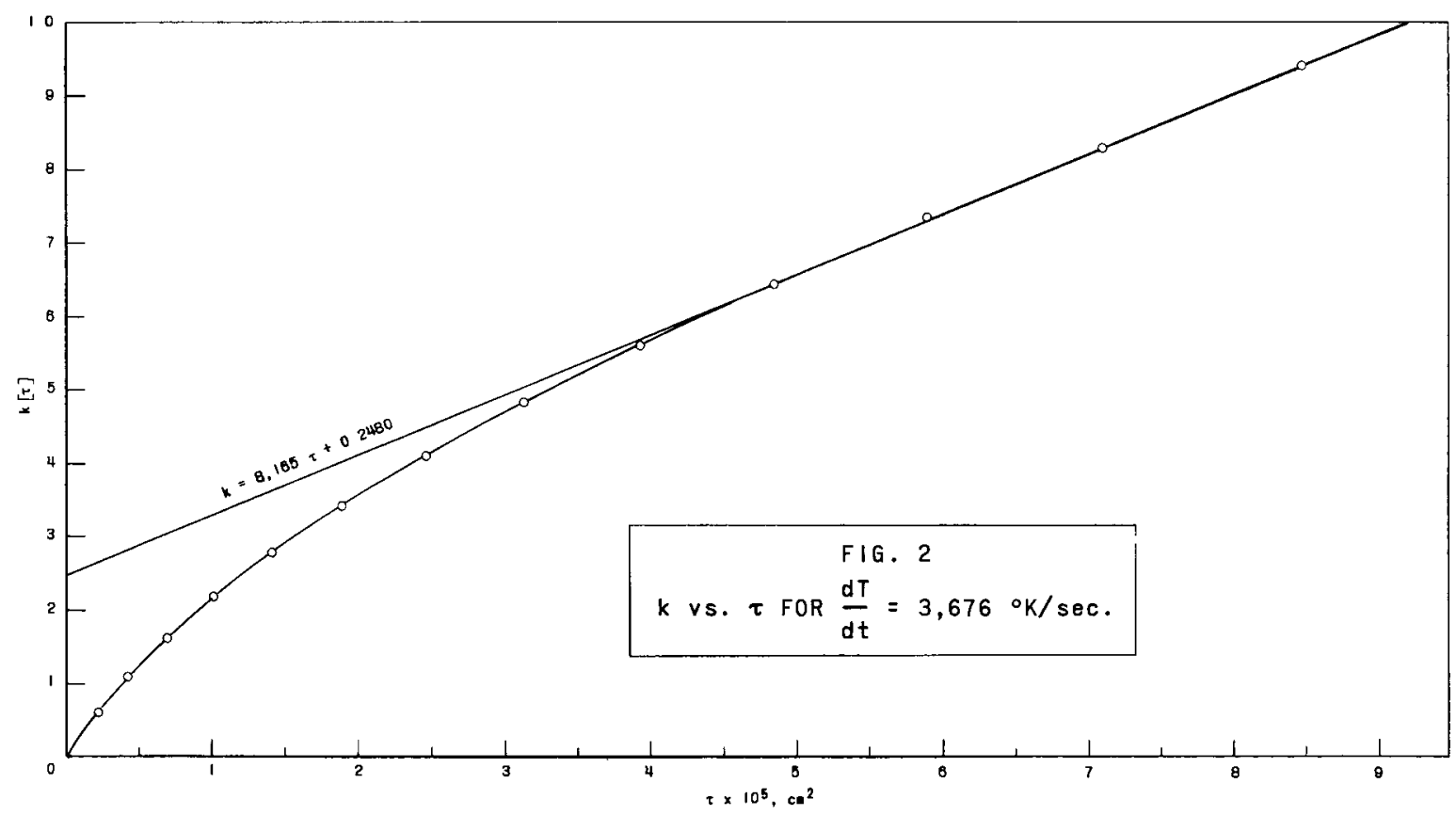

Since it is seen that for the range of input parameters of interest in these computations $\tau$ is always large, take $k$ to be given by Equation (II.19), where

$$
a=8,165.0
$$

and

$$
\mathrm{b}=0.2480
$$

It then follows from Section II.C that the dissolution equations for this system are given by Equations (III.1), (III.3), and (II.30). 
The following table is computed by means of the above equation (with $\bar{\rho}_{\mathrm{U}}=18.50 \mathrm{gm} / \mathrm{cm}^{3}$ ).

Table IV

Interface Recession for $\mathrm{dT} / \mathrm{dt}=3.676^{\circ} \mathrm{K} / \mathrm{sec}$

\begin{tabular}{|c|c|c|c|}
\hline $\mathrm{T}\left({ }^{\circ} \mathrm{K}\right)$ & $T \times 10^{5}$ & $\Delta \mathrm{L} \times 10^{3}(\mathrm{~cm})$ & $\mathrm{t}(\mathrm{sec})$ \\
\hline 1823 & 3.143 & 2.65 & 0.583 \\
1873 & 3.933 & 3.27 & 0.596 \\
1923 & 4.855 & 4.03 & 0.610 \\
1973 & 5.908 & 4.94 & 0.624 \\
2023 & 7.118 & 6.05 & 0.637 \\
2073 & 8.494 & 7.39 & 0.651 \\
2093 & 9.090 & 7.99 & 0.656 \\
\hline
\end{tabular}

It is seen that if the zirconium cladding thickness is $0.02286 \mathrm{~cm}$ (the thickness of the cladding employed in the EBR-II fuel pin), failure will occur in this system only after it attains the melting point of zirconium, under the conditions postulated; that is, the solid-liquid interface does not recede a distance equal to the cladding thickness before the model breaks down. It also is found that for the conditions specified, Equation (II.30) reduces to

$$
\frac{\Delta \mathrm{L}}{2}=\left(\frac{\tau}{\pi}\right)^{\frac{1}{2}}\left[\mathrm{~b}+\frac{2 \mathrm{a} \tau}{3}\right]
$$

Consider next the computation for $\mathrm{n}_{0}=1.0 \times 10^{9}$ neutrons $/ \mathrm{cm}^{3}$, corresponding to $\mathrm{dT} / \mathrm{dt}=367.6^{\circ} \mathrm{K} / \mathrm{sec}$. An examination of Equation (III.3) shows that here, for a given value of $\mathrm{T}$, the quantity $\tau$ is just greater by a factor of ten than it was for $n_{0}=1.0 \times 10^{10}$ neutrons $/ \mathrm{cm}^{3}$. Hence, Equation (II.19) again holds, with

$$
a=816.5
$$

and

$$
\mathrm{b}=0.2480
$$


Using the same procedure as before, the following table is computed:

Table V

Interface Recession for $\mathrm{dT} / \mathrm{dt}=367.6^{\circ} \mathrm{K} / \mathrm{sec}$

\begin{tabular}{|c|c|c|c|}
\hline $\mathrm{T}\left({ }^{\circ} \mathrm{K}\right)$ & $\tau \times 10^{4}$ & $\Delta \mathrm{L} \times 10^{-3}(\mathrm{~cm})$ & $\mathrm{t}(\mathrm{sec})$ \\
\hline 1823 & 3.143 & 8.38 & 5.83 \\
1873 & 3.933 & 10.34 & 5.96 \\
1923 & 4.855 & 12.75 & 6.10 \\
1973 & 5.908 & 15.63 & 6.24 \\
2023 & 7.118 & 19.14 & 6.37 \\
2073 & 8.494 & 23.37 & 6.51 \\
2093 & 9.090 & 25.27 & 6.56 \\
\hline
\end{tabular}

Interpolation of the above table shows that the solid-liquid interface recedes $0.02286 \mathrm{~cm}$ in $6.49 \mathrm{sec}$, at which time the liquid uranium has attained an average temperature of $2068^{\circ} \mathrm{K}\left(1795^{\circ} \mathrm{C}\right)$. It is also found for this case that Equation (II.30) reduces to Equation (III.5).

B. Case of Exponentially Increasing Reactor Power

The second application of the dissolution equations is to the case in which the neutron density in a reactor increases at an exponential rate with time, i.e.,

$$
\mathrm{n}=\mathrm{n}_{0} \mathrm{e}^{\lambda t}
$$

Then the average dissolution system temperature, based upon Equations (II.2) and (II. $2^{\prime}$ ), is

$$
T(t)=\frac{K \Sigma_{f} v n_{0}}{\rho_{U(l)} S_{U(\ell)^{\lambda}}}\left[e^{\lambda t}-1\right]+T_{0}-\left(T_{0}-T_{d}\right) \frac{\bar{\rho}_{U} \bar{S}_{U}}{\rho_{U}(\ell) S_{U}(\ell)} .
$$

Note here that for $\lambda t$ large, $T$ varies approximately exponentially with time. Define

$$
\omega=K \Sigma_{f} \vee n_{0} / \rho_{U(\ell)} S_{U(\ell)^{\lambda}} \quad ;
$$

and

$$
\phi=\omega+\left(\mathrm{T}_{0}-\mathrm{T}_{\mathrm{d}}\right) \frac{\bar{\rho}_{\mathrm{U}} \overline{\mathrm{S}}_{\mathrm{U}}}{\rho_{\mathrm{U}(\ell)} \mathrm{S}_{\mathrm{U}(\ell)}}-\mathrm{T}_{0}
$$


Then,

$$
T(t)=\omega e^{\lambda t}-\phi \quad,
$$

and

$$
\frac{\mathrm{dT}}{\mathrm{dt}}=\lambda(\mathrm{T}+\phi)
$$

Substitution of Equation (III.9) into Equation (II. 14) yields

$$
\begin{aligned}
\tau & =\frac{D_{0}}{\lambda} \int_{T_{0}}^{T} \frac{e^{-\epsilon / T^{\prime}}}{T^{\prime}+\phi} d T^{\prime} \\
& =\frac{D_{0}}{\lambda}\left\{-E i\left(-\frac{\epsilon}{T}\right)+e^{\epsilon / \phi} \operatorname{Ei}\left(-\frac{\epsilon}{\phi}\left[1+\frac{\phi}{T}\right]\right)+E i\left(-\frac{\epsilon}{T_{0}}\right)-e^{\epsilon / \phi} \operatorname{Ei}\left(-\frac{\epsilon}{\phi}\left[1+\frac{\phi}{T_{0}}\right]\right)\right\},
\end{aligned}
$$

where $-\operatorname{Ei}(-x)$ is defined by Equation (III.4).

As the first numerical computation for this case take

$$
\begin{aligned}
\lambda & =20.0 \mathrm{sec}^{-1} ; \\
\mathrm{n}_{0} & =50 \text { neutrons } / \mathrm{cm}^{3}\left(\begin{array}{c}
\text { corresponding to a power density of approxi- } \\
\text { mately } \left.10^{-6} \mathrm{watt} / \mathrm{cm}^{3}\right) .
\end{array}\right.
\end{aligned}
$$

Then:

$$
\begin{aligned}
& \omega=9.190 \times 10^{-7}{ }^{\circ} \mathrm{K}, \\
& \phi=319^{\circ} \mathrm{K},
\end{aligned}
$$

and

$$
T(t)=9.190 \times 10^{-7} e^{20.0 t}-319
$$

As in the first computation, take

$$
\begin{aligned}
\mathrm{D}_{0} & =0.1660 \mathrm{~cm}^{2} / \mathrm{sec} ; \\
\epsilon & =10,450^{\circ} \mathrm{K}
\end{aligned}
$$

Then,

$$
-\mathrm{Ei}\left(-\frac{\epsilon}{\mathrm{T}_{0}}\right)+\mathrm{e}^{\epsilon / \phi} \mathrm{Ei}\left(-\frac{\epsilon}{\phi}\left[1+\frac{\phi}{\mathrm{T}_{0}}\right]\right)=5.661 \times 10^{-5},
$$

and Equation (III.10) becomes: 


$$
\begin{aligned}
\tau(\mathrm{T})= & 0.830 \times 10^{-2}\left\{-\operatorname{Ei}\left(-\frac{10450}{\mathrm{~T}}\right)+1.6861 \times 10^{14} \mathrm{Ei}\left(-32.7568\left[1+\frac{319}{\mathrm{~T}}\right]\right)\right. \\
& \left.-5.661 \times 10^{-5}\right\}
\end{aligned}
$$

Using Equation (III.12) a table of $\tau$ vs $T$ is prepared:

Table VI

$\tau$ vs $\mathrm{T}$ for $\mathrm{dT} / \mathrm{dt}=20.0(\mathrm{~T}+319)^{\circ} \mathrm{K} / \mathrm{sec}$

\begin{tabular}{|c|c|c|c|c|c|}
\hline $\mathrm{T}\left({ }^{\circ} \mathrm{K}\right)$ & $\tau \times 10^{6}$ & $\mathrm{~T}\left({ }^{\circ} \mathrm{K}\right)$ & $\tau \times 10^{6}$ & $\mathrm{~T}\left({ }^{\circ} \mathrm{K}\right)$ & $\tau \times 10^{6}$ \\
\hline 1406 & 0 & 1650 & 1.203 & 1900 & 3.983 \\
1450 & 0.139 & 1700 & 1.609 & 1950 & 4.794 \\
1500 & 0.333 & 1750 & 2.084 & 2000 & 5.707 \\
1550 & 0.571 & 1800 & 2.634 & 2050 & 6.722 \\
1600 & 0.859 & 1850 & 3.265 & 2093 & 7.684 \\
\hline
\end{tabular}

By cross - referencing between Table VI and the previously determined values of $k$ as a function of $T$, a tabulation of $k$ vs $\tau$ is obtained:

Table VII

$\mathrm{k}$ vs $\tau$ for $\mathrm{dT} / \mathrm{dt}=20.0(\mathrm{~T}+319)^{\circ} \mathrm{K} / \mathrm{sec}$

\begin{tabular}{|c|c|c|c|c|c|}
\hline$\tau \times 10^{6}$ & $k$ & $\tau \times 10^{6}$ & $k$ & $\tau \times 10^{6}$ & $k$ \\
\hline 0 & 0 & 1.203 & 0.249 & 3.983 & 0.608 \\
0.139 & 0.040 & 1.609 & 0.314 & 4.794 & 0.695 \\
0.333 & 0.088 & 2.084 & 0.380 & 5.707 & 0.787 \\
0.571 & 0.137 & 2.634 & 0.452 & 6.722 & 0.891 \\
0.859 & 0.189 & 3.265 & 0.528 & 7.684 & 1.000 \\
\hline
\end{tabular}

These data are plotted in Fig. 3. It is seen that for $\tau$ large $k$ is linear in $\tau$. Hence, take $k$ to be given by Equation (II. 19), where

$$
\begin{aligned}
& a=1.0357 \times 10^{5} \\
& b=0.1940
\end{aligned}
$$

It again follows from Section II.C that the appropriate dissolution equations for this system are given by Equations (III.7), (III.10) and (II.30). 


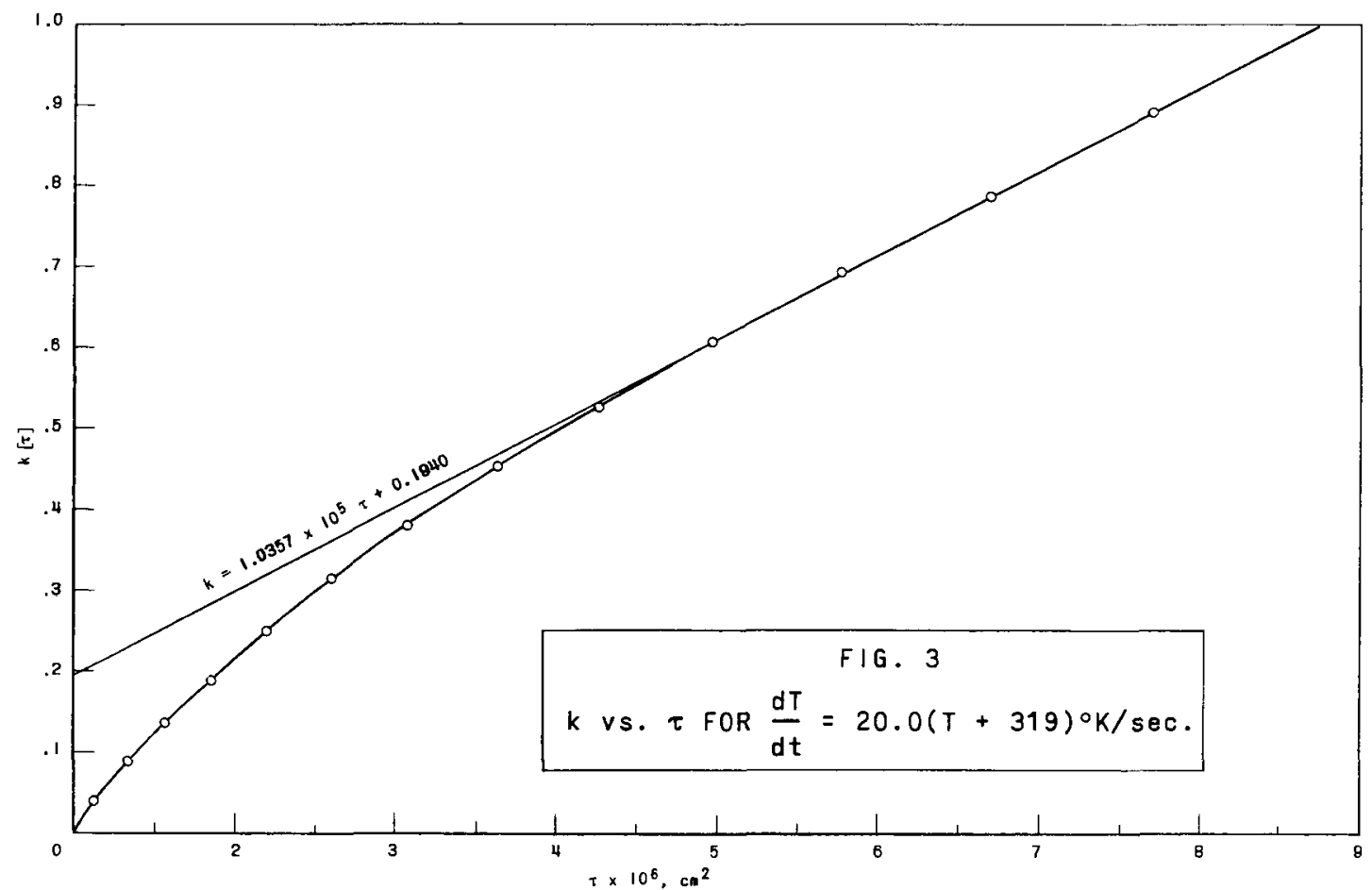

By means of the above equations, the following tabulation of the interface recession as a function of $\tau$ is made.

Table VIII

Interface Recession for $\mathrm{dT} / \mathrm{dt}=20.0(\mathrm{~T}+319)^{\circ} \mathrm{K} / \mathrm{sec}$

\begin{tabular}{|c|c|c|c|}
\hline $\mathrm{T}\left({ }^{\circ} \mathrm{K}\right)$ & $\tau \times 10^{6}$ & $\Delta \mathrm{L} \times 10^{3}(\mathrm{~cm})$ & $\mathrm{t}(\mathrm{sec})$ \\
\hline 1850 & 3.265 & 0.855 & 1.079 \\
1900 & 3.983 & 1.056 & 1.080 \\
1950 & 4.794 & 1.297 & 1.081 \\
2000 & 5.707 & 1.585 & 1.082 \\
2050 & 6.722 & 1.925 & 1.083 \\
2093 & 7.684 & 2.267 & 1.084 \\
\hline
\end{tabular}

These results indicate that if the zirconium cladding thickness is $0.02286 \mathrm{~cm}$, the cladding will fail by melting before complete dissolution into the molten uranium can occur.

As the second numerical computation for this case, take

$$
\begin{aligned}
\lambda & =0.10 \mathrm{sec}^{-1} ; \\
\mathrm{n}_{0} & =50 \text { neutrons } / \mathrm{cm}^{3}
\end{aligned}
$$


Then,

$$
\begin{aligned}
& \omega=1.838 \times 10^{-4}{ }^{\circ} \mathrm{K} \\
& \phi=319^{\circ} \mathrm{K} \quad ; \\
& \mathrm{T}=1.838 \times 10^{-4} \mathrm{e}^{0.10 \mathrm{t}}-319
\end{aligned}
$$

Since $\phi$ is essentially the same here as it was for the case of $\lambda=20.0 \mathrm{sec}^{-1}$, Equation (III.10) shows that $\tau$ is just two hundred times as great as it was for that case, i.e.,

$$
\begin{aligned}
& a=517.9 \\
& b=0.1940
\end{aligned}
$$

A tabulation of the interface recession as a function of $\tau$ is made for the above values of $a$ and $b$ :

\section{Table IX}

Interface Recession for $\mathrm{dT} / \mathrm{dt}=0.10(\mathrm{~T}+319)^{\circ} \mathrm{K} / \mathrm{sec}$

\begin{tabular}{|l|r|c|c|}
\hline $\mathrm{T}\left({ }^{\circ} \mathrm{K}\right)$ & $\tau \times 10^{4}$ & $\Delta \mathrm{L} \times 10^{3}(\mathrm{~cm})$ & $\mathrm{t}(\mathrm{sec})$ \\
\hline 1850 & 6.530 & 12.10 & 162.8 \\
1900 & 7.966 & 15.26 & 163.1 \\
1950 & 9.588 & 18.34 & 163.3 \\
2000 & 11.414 & 22.42 & 163.5 \\
2050 & 13.444 & 27.23 & 163.7 \\
2093 & 15.368 & 32.05 & 163.9 \\
\hline
\end{tabular}

Interpolation of the above table indicates that dissolution of the $0.02286-\mathrm{cm}$ thick zirconium cladding occurs in $163.5 \mathrm{sec}$, at which time the system has attained a temperature of $2004^{\circ} \mathrm{K}\left(1731^{\circ} \mathrm{C}\right)$. It is again found that, for the values of $D_{0}, \epsilon, L, \Delta L$, and $\lambda$ employed, Equation (II.30) reduces to Equation (III.5).

C. Case of Linearly Increasing Reactor Power

The third application of the dissolution equations is to the case in which the neutron density in a reactor increases linearly with time:

$$
n=n_{0}+2 n_{1} t
$$

According to Equations (II.2) and (II.2'), the average system temperature is

$$
\mathrm{T}(\mathrm{t})=\frac{\mathrm{K} \Sigma_{\mathrm{f}} \mathrm{vn}_{\mathrm{I}}}{\rho_{\mathrm{U}(\ell)} \mathrm{S}_{\mathrm{U}(\ell)}} t^{2}+\frac{\mathrm{K} \Sigma_{\mathrm{f}} \mathrm{vn}_{0}}{\rho_{\mathrm{U}(\ell)} \mathrm{S}_{\mathrm{U}(l)}} \mathrm{t}+\mathrm{T}_{\mathrm{o}}-\left(\mathrm{T}_{0}-\mathrm{T}_{\mathrm{d}}\right) \frac{\bar{\rho}_{\mathrm{U}} \overline{\mathrm{S}}_{\mathrm{U}}}{\rho_{\mathrm{U}(\ell)} \mathrm{S}_{\mathrm{U}(\ell)}} .
$$


Note here that $T(t)$ varies parabolically with time. Also, it is readily shown that

$\frac{\mathrm{dT}}{\mathrm{dt}}=\sqrt{\left(\frac{\mathrm{K} \Sigma_{\mathrm{f}} \vee n_{0}}{\rho_{\mathrm{U}(\ell)} \mathrm{S}_{\mathrm{U}(\ell)}}\right)^{2}+\frac{4 \mathrm{~K} \Sigma_{\mathrm{f} \vee n_{1}}}{\rho_{\mathrm{U}(\ell)} \mathrm{S}_{\mathrm{U}(\ell)}}\left[\mathrm{T}+\left(\mathrm{T}_{0}-\mathrm{T}_{\mathrm{d}}\right) \frac{\bar{\rho}_{\mathrm{U}} \overline{\mathrm{S}}_{\mathrm{U}}}{\rho_{\mathrm{U}(\ell)} \mathrm{S}_{\mathrm{U}(\ell)}}-\mathrm{T}_{0}\right]}$.

Substitution of Equation (III.15) into Equation (II.14) yields

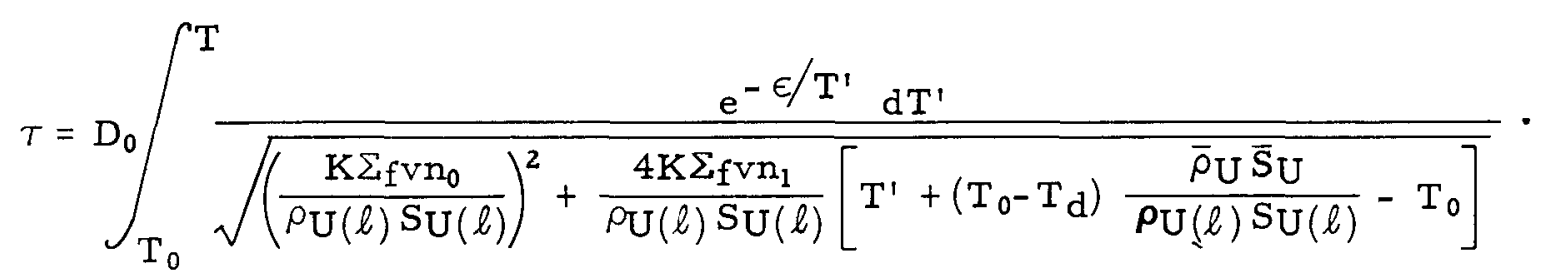

In the first numerical computation for this case take

$$
\begin{aligned}
& \mathrm{n}_{0}=50 \text { neutrons } / \mathrm{cm}^{3} ; \\
& \mathrm{n}_{1}=5.0 \times 10^{8} \text { neutrons } /\left(\mathrm{cm}^{3}\right)(\mathrm{sec})
\end{aligned}
$$

Neglecting the initial neutron density for elapsed times greater than one millisecond, Equation (III.16) becomes

$$
\tau=\frac{D_{0}}{\sqrt[2]{\frac{K \Sigma_{\mathrm{f} V n_{1}}}{\rho_{\mathrm{U}(\ell)} \mathrm{S}_{\mathrm{U}(\ell)}}}} \int_{\mathrm{T}_{0}}^{\mathrm{T}} \frac{\mathrm{e}^{-\epsilon / \mathrm{T}^{\prime}} \mathrm{dT}^{\prime}}{\sqrt{\mathrm{T}^{\prime}+\left(\mathrm{T}_{0}-\mathrm{T}_{\mathrm{d}}\right) \frac{\bar{\rho}_{\mathrm{U}} \overline{\mathrm{S}}_{\mathrm{U}}}{\rho_{\mathrm{U}(\ell)} \mathrm{S}_{\mathrm{U}}(\ell)}-\mathrm{T}_{0}}} .
$$

Substitution of the previously given values of $D_{0}, \epsilon$ and $K \Sigma_{f} / \rho_{U}(l) S_{U}(\ell)$ into the above equation yields

$$
\tau=6.122 \times 10^{-3} \int_{1406}^{\mathrm{T}} \frac{\mathrm{e}^{-10450 / \mathrm{T}^{\prime}}}{\sqrt{\mathrm{T}^{\prime}+319}} \mathrm{~T}^{\prime}
$$


The following table is prepared by a graphical integration of Equation (III.18):

Table X

$T$ vs $\mathrm{T}$ for $\mathrm{dT} / \mathrm{dt}=27.12 \sqrt{\mathrm{T}+319}{ }^{\circ} \mathrm{K} / \mathrm{sec}$

\begin{tabular}{|c|c|c|c|c|c|}
\hline $\mathrm{T}\left({ }^{\circ} \mathrm{K}\right)$ & $\tau \times 10^{5}$ & $\mathrm{~T}\left({ }^{\circ} \mathrm{K}\right)$ & $\tau \times 10^{5}$ & $\mathrm{~T}\left({ }^{\circ} \mathrm{K}\right)$ & $\tau \times 10^{5}$ \\
\hline 1406 & 0 & 1650 & 3.822 & 1900 & 13.234 \\
1450 & 0.426 & 1700 & 5.159 & 1950 & 16.069 \\
1500 & 1.030 & 1750 & 6.741 & 2000 & 19.289 \\
1550 & 1.787 & 1800 & 8.598 & 2050 & 22.915 \\
1600 & 2.707 & 1850 & 10.753 & 2093 & 26.950 \\
\hline
\end{tabular}

Using the previously given values of $k$ vs $T$, a table of $k$ vs $\tau$ is prepared:

Table XI

$\mathrm{k}$ vs $T$ for $\mathrm{dT} / \mathrm{dt}=27.12 \sqrt{\mathrm{T}+319}{ }^{\circ} \mathrm{K} / \mathrm{sec}$

\begin{tabular}{|c|c|c|c|c|c|}
\hline $\mathrm{k}$ & $\tau \times 10^{5}$ & $\mathrm{k}$ & $\tau \times 10^{5}$ & $\mathrm{k}$ & $\tau \times 10^{5}$ \\
\hline 0 & 0 & 0.249 & 3.822 & 0.608 & 13.234 \\
0.040 & 0.426 & 0.314 & 5.159 & 0.695 & 16.069 \\
0.088 & 1.030 & 0.380 & 6.741 & 0.787 & 19.289 \\
0.137 & 1.787 & 0.452 & 8.598 & 0.891 & 22.915 \\
0.189 & 2.707 & 0.528 & 10.753 & 1.000 & 26.950 \\
\hline
\end{tabular}

These results are plotted in Fig. 4, from which it is seen that for $\tau$ large $\mathrm{k}$ is linear in $\tau$.

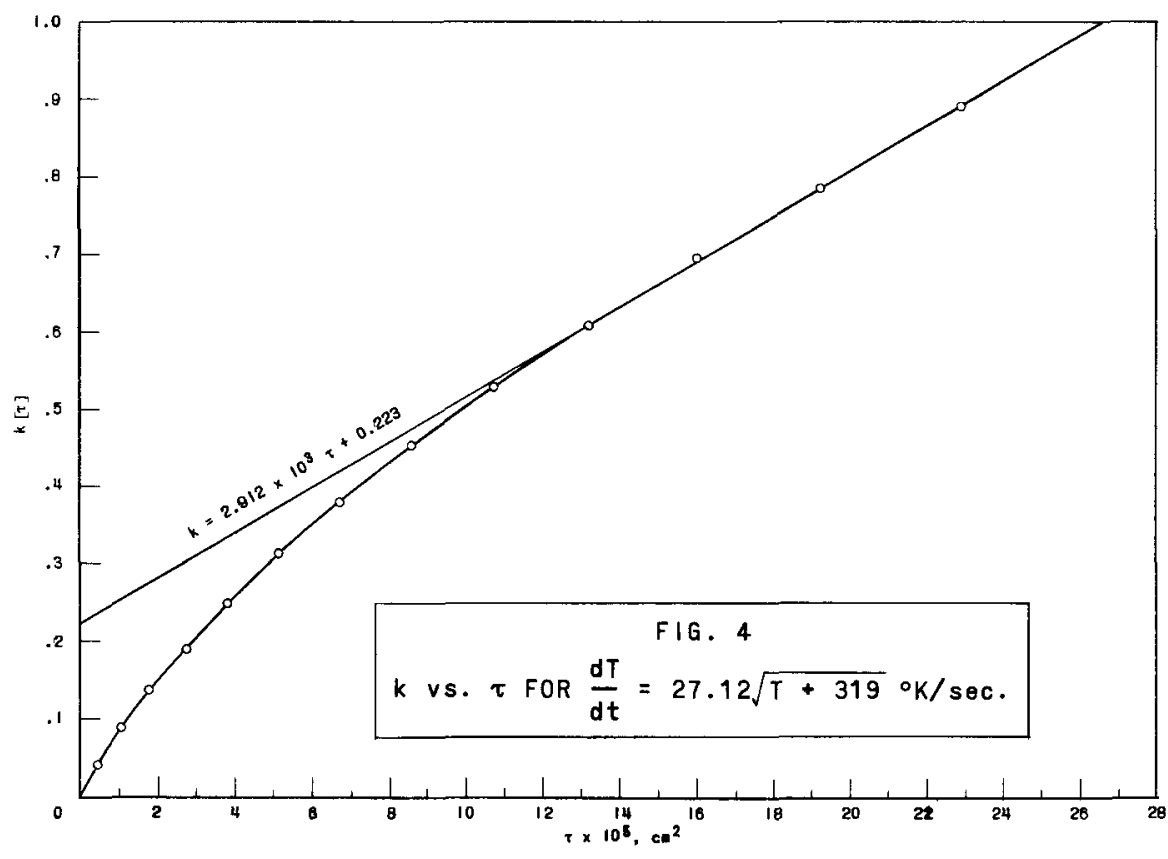


Thus $\mathrm{k}(\tau)$ may again be approximated by Equation (II.19) with

$$
\begin{aligned}
& a=2.912 \times 10^{3} \quad ; \\
& b=0.223 .
\end{aligned}
$$

Employing the appropriate dissolution Equations (III.14), (III.17) and (II.30) the following table of recession of the solid-liquid interface is computed:

Table XII

Interface Recession for $\mathrm{dT} / \mathrm{dt}=27.12 \sqrt{\mathrm{T}+319}{ }^{\circ} \mathrm{K} / \mathrm{sec}$

\begin{tabular}{|c|c|c|c|}
\hline $\mathrm{T}\left({ }^{\circ} \mathrm{K}\right)$ & $\tau \times 10^{5}$ & $\Delta \mathrm{L} \times 10^{3}(\mathrm{~cm})$ & $\mathrm{t}(\mathrm{sec})$ \\
\hline 1850 & 10.753 & 5.05 & 3.44 \\
1900 & 13.234 & 6.23 & 3.47 \\
1950 & 16.069 & 7.65 & 3.51 \\
2000 & 19.289 & 9.36 & 3.55 \\
2050 & 22.915 & 11.41 & 3.59 \\
2093 & 26.950 & 13.82 & 3.62 \\
\hline
\end{tabular}

If the zirconium cladding thickness is $0.02286 \mathrm{~cm}$, the above computations show that for the postulated conditions the cladding will fail by melting before it dissolves completely into the molten uranium.

Consider next the computation for $\mathrm{n}_{1}=5.0 \times 10^{7}$ neutrons $/\left(\mathrm{cm}^{3}\right)(\mathrm{sec})$, corresponding to $\mathrm{dT} / \mathrm{dt}=8.576 \sqrt{\mathrm{T}+319}{ }^{\circ} \mathrm{K} / \mathrm{sec}$. An examination of Equation (III.17) shows that for $n_{1}=5.0 \times 10^{7}$ neutrons $/\left(\mathrm{cm}^{3}\right)(\mathrm{sec}), \tau$ is just $\sqrt{10}$ greater than it is for $n_{1}=5.0 \times 10^{8}$ neutrons $/\left(\mathrm{cm}^{3}\right)(\mathrm{sec})$, and hence for this new case,

$$
\begin{aligned}
& \mathrm{a}=920.8 \quad ; \\
& \mathrm{b}=0.223 \quad
\end{aligned}
$$

The following table was computed using the above information:

Table XIII

Interface Recession for $\mathrm{dT} / \mathrm{dt}=8.576 \sqrt{\mathrm{T}+319}{ }^{\circ} \mathrm{K} / \mathrm{sec}$

\begin{tabular}{|c|c|c|c|}
\hline $\mathrm{T}\left({ }^{\circ} \mathrm{K}\right)$ & $\tau \times 10^{4}$ & $\Delta \mathrm{L} \times 10^{3}(\mathrm{~cm})$ & $\mathrm{t}(\mathrm{sec})$ \\
\hline 1850 & 3.401 & 8.98 & 10.86 \\
1900 & 4.185 & 11.08 & 10.99 \\
1950 & 5.082 & 13.60 & 11.11 \\
2000 & 6.100 & 16.64 & 11.23 \\
2050 & 7.247 & 20.29 & 11.35 \\
2093 & 8.523 & 24.58 & 11.46 \\
\hline
\end{tabular}


Interpolation of the above table shows that for this case the zirconium cladding dissolves in $11.43 \mathrm{sec}$, at which time the liquid uranium has reached $2077^{\circ} \mathrm{K}\left(1804^{\circ} \mathrm{C}\right)$. It is noteworthy that here again, for the range of parameters studied, Equation (II.30) reduces to Equation (III.5).

D. Discussion of Observed Linearity of $\mathbf{k}$ with $T$

One of the most important results of this study is the observed linearity of $\mathbf{k}$ with $\tau$, at the larger values of $\tau$, for each of the three variations of reactor power treated. The following analysis gives some insight into this result.

Differentiation of Equation (II.19) with respect to $\tau$ gives

$$
\frac{d k}{d \tau}=a=\frac{d k}{d T} / \frac{d \tau}{d T}
$$

According to Equation (III.19), if $\mathrm{k}$ is linear in $\tau$, then the ratio $(\mathrm{dk} / \mathrm{dT}) /(\mathrm{d} \tau / \mathrm{dT})$ is constant. expression

At the higher temperatures $k[\mathrm{~T}]$ can be represented closely by the

$$
k=m_{0}+m_{1} T+m_{2} T^{2}
$$

The following correlation of numerical values holds:

$$
\begin{array}{rlrl}
\mathrm{k} & =0.563 & \mathrm{~T} & =1873^{\circ} \mathrm{K} ; \\
& =0.736 & & =1973^{\circ} \mathrm{K} ; \\
& =0.942 & & =2073^{\circ} \mathrm{K} ;
\end{array}
$$

Substituting the above values into Equation (III.20) and solving yields the values

$$
\begin{aligned}
& \mathrm{m}_{0}=3.4204 ; \\
& \mathrm{m}_{1}=-4.616 \times 10^{-3} \\
& \mathrm{~m}_{2}=1.650 \times 10^{-6}
\end{aligned}
$$

Substituting these values into Equation (III.20) and differentiating with respect to $\mathrm{T}$, there is obtained

$$
\frac{\mathrm{dk}}{\mathrm{dT}}=3.30 \times 10^{-6}(\mathrm{~T}-1399)
$$

Equation (III.2l) shows that for $k$ to be linear in $\tau$, the quantity $d \tau / d T$ must be proportional to ( $T$ - 1399). 
It can be shown that $\mathrm{dT} / \mathrm{d} \tau$ varies much less rapidly with $\mathrm{T}$ than does $e^{-\epsilon} / T$ for the values of $D_{0}, \epsilon$ and $K \Sigma_{f v} / \rho_{U}(\ell) S_{U}(\ell)$ employed, and the ranges of $n_{0}, \lambda$, and $n$ considered. Then, referring to Equations (II.12) and (II.13), an average value, $\tau$, of $\mathrm{dT} / \mathrm{dt}$ exists, such that for any chosen range of $\mathrm{T}$

$$
\frac{\mathrm{d} \tau}{\mathrm{dT}}=\frac{\mathrm{D}_{0}}{\zeta} \mathrm{e}^{-\epsilon / \mathrm{T}}
$$

Thus $k$ is linear in $\tau$ to the extent that $e^{-\epsilon / T}$ is proportional to ( $T-1399$ ) in the range of temperature considered.

Substituting Equations (III.21) and (III.22) into (III.19) and employing the previously given values of $D_{0}$ and $\epsilon$,

$$
\frac{\mathrm{dk}}{\mathrm{d} \tau}=\frac{3.30 \times 10^{-6} \zeta}{\mathrm{D}_{0}}\left(\frac{\mathrm{T}-1399}{\mathrm{e}^{-\epsilon / T}}\right)=1.988 \times 10^{-5} \zeta\left(\frac{\mathrm{T}-1399}{\mathrm{e}^{-10450 / T}}\right)
$$

The quantity $\frac{\mathrm{l}}{\zeta} \frac{\mathrm{dk}}{\mathrm{d} \tau}$ is computed in the following table by means of Equation (III.23):

Table XIV

Computation of $\frac{\mathrm{l}}{\zeta} \frac{\mathrm{dk}}{\mathrm{d} \tau}$ vs $\mathrm{T}$

\begin{tabular}{|c|c|c|c|}
\hline $\mathrm{T}$ & $1.988 \times 10^{-5}(\mathrm{~T}-1399)$ & $\mathrm{e}^{-10450 / \mathrm{T}}$ & $\frac{1}{\zeta} \frac{\mathrm{dk}}{\mathrm{dT}}$ \\
\hline 1873 & $9.423 \times 10^{-3}$ & $3.7752 \times 10^{-3}$ & 2.496 \\
1923 & $10.417 \times 10^{-3}$ & $4.3651 \times 10^{-3}$ & 2.386 \\
1973 & $11.411 \times 10^{-3}$ & $5.0090 \times 10^{-3}$ & 2.278 \\
2023 & $12.405 \times 10^{-3}$ & $5.7097 \times 10^{-3}$ & 2.173 \\
2073 & $13.399 \times 10^{-3}$ & $6.4675 \times 10^{-3}$ & 2.071 \\
2093 & $13.797 \times 10^{-3}$ & $6.7866 \times 10^{-3}$ & 2.033 \\
\hline
\end{tabular}

The last column of the above table gives a measure of the departure from proportionality to $(T-1399)$ exhibited by $e^{-\epsilon} / \mathrm{T}$ in the indicated range of temperature. In this range the arithmetic mean value of $1 / \zeta \mathrm{dk} / \mathrm{d} \tau$ is found to be 2.240 . Then

$$
\mathrm{a}=\frac{\mathrm{dk}}{\mathrm{d} \tau} \approx 2.240 \zeta
$$


For the first numerical computation in the constant power case,

$$
\zeta=\mathrm{K} \Sigma_{\mathrm{f}} \mathrm{n}_{0} / \rho_{\mathrm{U}}(\ell) \mathrm{S}_{\mathrm{U}(\ell)}=3,676^{\circ} \mathrm{K} / \mathrm{sec}
$$

Then

$$
\frac{\mathrm{dk}}{\mathrm{d} \tau}=2.240 \times 3,676=8,234
$$

The value of a calculated from Fig. 2 is 8,165 .

For the first numerical computation in the exponential power case (taking the arithmetic mean value of $\mathrm{T}$ as $1993^{\circ} \mathrm{K}$ ),

$$
\zeta=\lambda(T+\phi)=20(1993+319)=4.624 \times 10^{4},
$$

and

$$
\frac{\mathrm{dk}}{\mathrm{d} \tau}=2.240 \times 4.624 \times 10^{4}=1.036 \times 10^{5}
$$

The value of a calculated from Fig. 3 is $1.036 \times 10^{5}$.

For the first numerical calculation in the linear power case (employing the same mean value of $\mathrm{T}$ as above),

$$
\zeta=\sqrt[2]{\frac{\mathrm{K} \Sigma_{f^{v n_{1}}}}{\rho_{\mathrm{U}(\ell)^{\mathrm{S}} \mathrm{U}(\ell)}}\left[\mathrm{T}+\left(\mathrm{T}_{0}-\mathrm{T}_{\mathrm{d}}\right) \frac{\bar{\rho}_{\mathrm{U}} \overline{\mathrm{S}}_{\mathrm{U}}}{\rho_{\mathrm{U}(\ell)} \mathrm{S}_{\mathrm{U}(\ell)}}-\mathrm{T}_{0}\right]}=1304^{\circ} \mathrm{K} / \mathrm{sec} \text {, }
$$

and

$$
\frac{\mathrm{d} k}{\mathrm{~d} \tau}=2.240 \times 1304=2,921
$$

The value of a calculated from Fig. 4 is 2,912 .

Thus for any physically meaningful case where $\mathrm{dT} / \mathrm{d} \tau$ varies much less rapidly with $\mathrm{T}$ than does $\mathrm{e}^{-\epsilon} / \mathrm{T}$, the solution of the system of Equations (II.15)-(II.18) is given by Equation (II.27). Also, Equation (III.24) may be employed to give an approximate check on the value of a determined from the graph of $\mathrm{k}$ vs $\tau$.

\section{CONCLUSIONS}

A model that permits an estimate to be made of the time required for molten uranium to penetrate zirconium cladding under various conditions of fission heat generation in the uranium has been developed. The 
dissolution equations describing this model are valid for any form of fission heat generation where the time rate of change of temperature, expressed as a function of temperature, varies much less rapidly with temperature than $e^{-\epsilon / T}$.

The model indicates that, for large time rates of change of temperature, corresponding to large fission heat generation rates, failure is by direct melting of the cladding rather than by progressive interaction with the molten uranium. For a given form of time rate of change of temperature, i.e., constant, exponential or linear, there exists a critical value of time rate of change of temperature below which failure occurs solely by progressive dissolution of the cladding, and above which failure occurs by direct melting of the cladding remaining, according to the model postulated. This critical value corresponds to the case in which dissolution of the cladding is completed at the instant when the molten uranium reaches the cladding melting point.

The dissolution time predicted by a rectangular, finite geometry is always less than that predicted by a cylindrical, finite geometry. The reason for this may be seen by computing the increase in concentration of zirconium in the molten uranium of extent $r$, due to the dissolution of a small thickness, $\Delta r$, of the zirconium into the uranium:

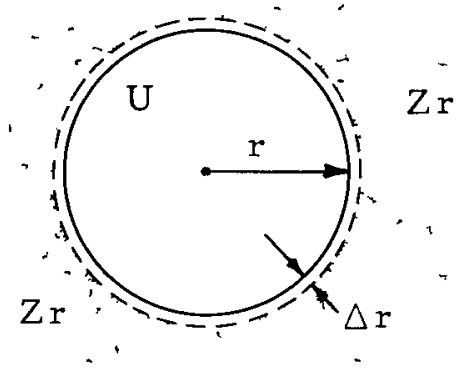

$$
\begin{aligned}
\Delta \mathrm{c} & =\frac{2 \pi \mathrm{r} \Delta \mathrm{r}(1 \mathrm{~cm})}{\pi \mathrm{r}^{2}(1 \mathrm{~cm})} \rho_{\mathrm{Zr}} \\
& =2 \frac{\Delta \mathrm{r}}{\mathrm{r}} \rho_{\mathrm{Zr}}
\end{aligned}
$$

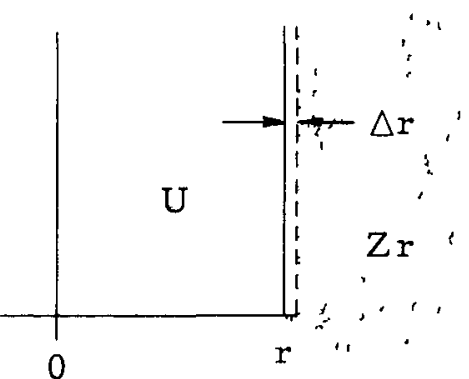$$
\Delta c=\frac{\Delta r\left(1 \mathrm{~cm}^{2}\right)}{r\left(1 \mathrm{~cm}^{2}\right)} \rho_{\mathrm{Zr}}
$$$$
=\frac{\Delta r}{r} \rho_{Z r}
$$

Thus, a given recession of the solid-liquid interface will cause the bulk average concentration of zirconium in the molten uranium to increase twice as much in the cylindrical geometry as it will in the rectangular geometry. But the more concentrated the solution 1s, the smaller the driving force for dissolution becomes. Hence, the dissolution rate is always smaller in the cylindrical geometry. From this it follows that the dissolution times computed for the rectangular geometry in this report 
represent a lower limit to the dissolution time for a cylindrical geometry. However, it should not be assumed that the dissolution time predicted by the finite cylindrical geometry will be exactly larger by a factor of two than that predicted by the finite rectangular geometry, as the exact value of this factor will depend upon the dimensions of the system considered (the factor is 1.63 for the examples treated in Section IA).

The equations derived in this report can be employed to produce graphs that permit the rapid estimation of the time required for complete dissolution of the cladding into the molten uranium. Such graphs were not produced as a part of the present study because of the tentative nature of the values of $D_{0}$ and $\epsilon$ employed in the computations.

The dissolution equations derived in this study for zirconium as the cladding material should be applicable to any metal cladding for which the equilibrium solubility of that material in molten uranium is a monotonically increasing function of temperature and for which the solid-liquid interaction is describable in terms of the diffusion equations. Some examples of such materials are niobium, tantalum, titanium and tungsten.

In conclusion, the cladding dissolution equations derived in this study have two probable areas of application. First, they may serve as a basis for the interpretation of experimental data on the dissolutiondependent failure of uranium fuel pins clad with certain refractory metals. Second, given the results of the above experiments, the equations may be employed to predict the failure time, resulting from a reactor accident, of such fuel pins in a fast reactor core. 


\section{APPENDIX A}

Derivation of One-dimensional Rectangular Finite Geometry, Constant-temperature, Diffusion-controlled Dissolution Equation

Consider the dissolution system below:

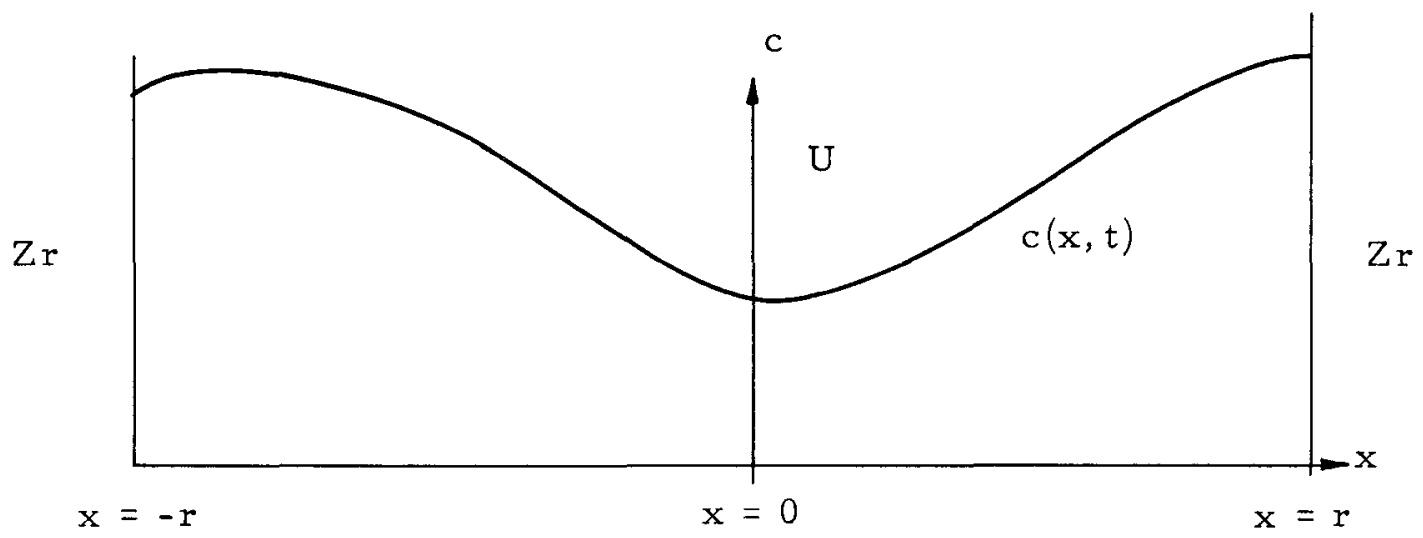

For this system let

$$
\begin{array}{ll}
\frac{\partial c}{\partial t}=D \frac{\partial^{2} c}{\partial x^{2}} ;-r<x<r ; t \geq 0 & \text { (diffusion equation) } \\
c(x, 0)=0 ;-r<x<r & \text { (initial condition) } \\
c(r, t)=\rho_{Z r} k(T) ; t \geq 0 & \text { (interface condition) } \\
\left.\frac{\partial c}{\partial x}\right|_{x=0}=0 ; t \geq 0 & \text { (symmetry condition) }
\end{array}
$$

Define the Laplace transform of $c(x, t)$ :

$$
L\{c(x, t)\} \equiv \int_{0}^{\infty} c(x, t) e^{-P t} d t=\bar{c}(x, P) .
$$

Taking the Laplace transform of the diffusion equation above and making use of the initial condition,

$$
P \bar{c}=D \frac{\partial 2 \bar{c}}{\partial x^{2}},
$$


whence

$$
\bar{c}=A e^{-\sqrt{P / D} x}+B e^{\sqrt{P / D} x} .
$$

Employing the symmetry condition it is found that $A=B$; thus

$$
\bar{c}=A\left(e^{-\sqrt{P / D} x}+e^{\sqrt{P / D} x}\right) .
$$

Employing the interface condition,

$$
A=\frac{\rho_{Z_{r} k(T)}}{P_{e} \sqrt{P / D} r\left(1+e^{-2} \sqrt{P / D} r\right)}=\frac{\rho_{Z x}{ }^{k(T)}}{P} e^{-\sqrt{P / D} r} \sum_{n=0}^{\infty}(-1)^{n} e^{-2 n r} \sqrt{P / D} .
$$

Thus,

$$
c(x, p)=\frac{\rho_{Z r} k(T)}{P} \sum_{n=0}^{\infty}(-1)^{n}\left\{e^{-[r(2 n+1)+x]} \sqrt{P / D}+e^{-[r(2 n+1)-x]} \sqrt{P / D}\right\},
$$

and

$$
c(x, t)=\rho_{Z r} k(T) \sum_{n=0}^{\infty}(-1)^{n}\left\{\operatorname{erfc}\left[\frac{(2 n+1) r+x}{2 \sqrt{D t}}\right]+\operatorname{erfc}\left[\frac{(2 n+1) r-x}{2 \sqrt{D t}}\right]\right\} .
$$

A mass balance gives

$$
\Delta r=k(T) \sum_{0}^{r} \sum_{n=0}^{\infty}(-1)^{n}\left\{\operatorname{erfc}\left[\frac{(2 n+1) r+x}{2 \sqrt{D t}}\right]+\operatorname{erfc}\left[\frac{(2 n+1) r-x}{2 \sqrt{D t}}\right]\right\} .
$$

Setting

$$
\frac{r}{2 \sqrt{\mathrm{Dt}}}=\alpha
$$


it is found that

$$
\begin{aligned}
\frac{\alpha}{\mathrm{k}(\mathrm{T})} \frac{\Delta \mathrm{r}}{\mathrm{r}}= & \sum_{\mathrm{n}=0}^{\infty}(-1)^{\mathrm{n}}\{2 \alpha-[2(\mathrm{n}+1) \alpha] \operatorname{erf}[2(\mathrm{n}+1) \alpha]+(2 \mathrm{n} \alpha) \operatorname{erf}(2 \mathrm{n} \alpha) \\
& \left.+\frac{1}{\sqrt{\pi}}\left[\mathrm{e}^{-(2 \mathrm{n} \alpha)^{2}}-\mathrm{e}^{-[2(\mathrm{n}+1) \alpha]^{2}}\right]\right\} .
\end{aligned}
$$




\section{APPENDIX B}

Derivation of One-Dimensional, Cylindrical Finite Geometry, Constant-temperature, Diffusion-controlled Dissolution Equation

Consider the dissolution system below:

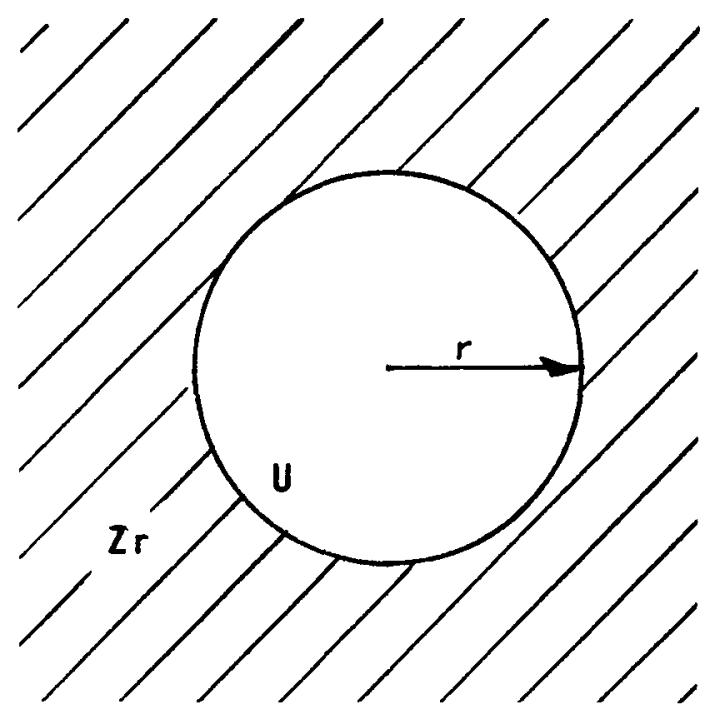

For this system let:

$$
\begin{array}{ll}
\frac{1}{D} \frac{\partial c}{\partial t}=\frac{\partial^{2} c}{\partial r^{2}}+\frac{1}{r} \frac{\partial c}{\partial r} ; r<R ; t \geq 0 & \text { (diffusion equation) } \\
c(r, 0)=0 ; r<R & \text { (initial condition) } \\
c(R, t)=\rho_{Z r} k(T) ; t \geq 0 & \text { (interface condition) } \\
\left.\frac{\partial c}{\partial r}\right|_{r=0}=0 ; t \geq 0 & \text { (symmetry condition). }
\end{array}
$$

Define the Laplace transform of $c(r, t)$ :

$$
L\{c(r, t)\} \equiv \int_{0}^{\infty} c(r, t) e^{-P t} d t=\bar{c}(r, P)
$$

Taking the Laplace transform of the diffusion equation and utilizing the initial condition, 


$$
\frac{P}{D} \bar{c}=\frac{\partial^{2} \bar{c}}{\partial r^{2}}+\frac{1}{r} \frac{\partial \bar{c}}{\partial r}
$$

and

$$
\bar{c}(r, P)=A_{0}(\sqrt{P / D} r)+B K_{0}(\sqrt{P / D} r)
$$

Employing the symmetry condition it is found that $B=0$; thus,

$$
\bar{c}(\mathbf{r}, \mathrm{P})=\mathrm{AI}_{0}(\sqrt{\mathrm{P} / \mathrm{D}} \mathbf{r})
$$

Employing the interface condition,

$$
\mathrm{A}=\rho_{\mathrm{Zr}} \mathrm{k}(\mathrm{T}) / \mathrm{PI}_{0}(\sqrt{\mathrm{P} / \overline{\mathrm{D}} \mathrm{R})}
$$

and

$$
c(r, P)=\frac{\rho_{Z_{r}} k(T)}{\mathrm{PI}_{0}(\sqrt{P / D} R)} I_{0}(\sqrt{P / D} r),
$$

whence (12)

$$
c(r, t)=\rho_{Z r} k(T)\left[1-\frac{2}{R} \sum_{n=1}^{\infty} e^{-D \beta_{n}^{2} t} \frac{J_{0}\left(r \beta_{n}\right)}{\beta_{n} J_{1}\left(R \beta_{n}\right)}\right],
$$

where the $\beta_{\mathrm{n}}$ are the roots of

$$
\mathrm{J}_{0}\left(\mathrm{R} \beta_{\mathrm{n}}\right)=0
$$

A mass balance gives

$$
R \Delta R=k(T) \int_{0}^{R}\left[1-\frac{2}{R} \sum_{n=1}^{\infty} e^{-D \beta_{n}^{2} t} \frac{J_{0}\left(r \beta_{n}\right)}{\beta_{n} J_{1}\left(R \beta_{n}\right)}\right] d r
$$

whence

$$
\frac{\Delta R}{R}=k(T)\left[\frac{1}{2}-\frac{2}{R^{2}} \sum_{n=1}^{\infty} \frac{1}{\beta_{n}^{2}} e^{-D \beta_{n}^{2} t}\right]
$$




\section{Estimation of $\mathrm{D}_{0}$ and $\epsilon$}

If only one value of $\mathrm{D}$ as a function of $\mathrm{T}$ is available for a given diffusion system, then the semi-empirical Langmuir-Dushman equation may be employed $(11)$ to estimate $D_{0}$ and $E$ :

$$
\mathrm{D}=\frac{E d^{2}}{N_{0} h} e^{-E / R T},
$$

where

$$
\begin{aligned}
\mathrm{N}_{0} & =\text { Avogadro's number, } 6.025 \times 10^{23} \text { atoms } / \mathrm{gm} \text { atom } \\
\mathrm{d} & =\text { interatomic distance, } \mathrm{cm} \\
\mathrm{h} & =\text { Planck's constant. }
\end{aligned}
$$

Here take $\mathrm{d}=2.76 \times 10^{-8} \mathrm{~cm}$ for the uranium. Then

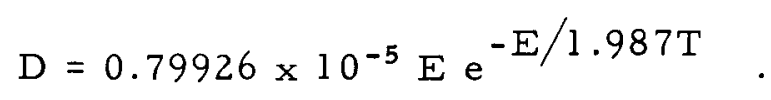

Substituting $D\left[1543^{\circ} \mathrm{K}\right]=1.9 \times 10^{-4} \mathrm{~cm}^{2} / \mathrm{sec}$, and taking the logarithm of the resulting equation,

$$
\log E-\frac{E}{7059.5}=1.37605
$$

Solution of the above transcendental equation yields

$$
\begin{aligned}
E & =20,764 \mathrm{cal} / \mathrm{mole} \\
D_{0} & =0.16596 \mathrm{~cm}^{2} / \mathrm{sec} \\
\epsilon & =E / R=10,450^{\circ} \mathrm{K} .
\end{aligned}
$$




\section{BIBLIOGRAPHY}

1. McCarthy, W. J., Nicholson, R. D., Okrent, D., and Jankus, V. F., Studies of Nuclear Accidents in Fast Power Reactors, Proc. of the Second UN International Conference on the Peaceful Uses of Atomic Energy, Geneva (1958), Vol. 12, p. 207.

2. Golden, G. H., Kinetics of Dissolution of Zirconium in Molten Uranium, ANL-6167 (May 1960).

3. Rough, F. A., and Bauer, A. A., Constitution of Uranium and Thorium Alloys, BMI-1300 (June 2, 1958).

4. Jost, W., Diffusion in Solids, Liquids, and Gases, Academic Press, New York (1952), p.459.

5. Crank, J., The Mathematics of Diffusion, Oxford (1956), p. 327.

6. Lowan, A. N., N.B.S. Tables of Sine, Cosine and Exponential Integrals, Vol. II (1940).

7. Akahira, T., Tables of $\frac{e^{-x}}{x}$ and $\int_{x}^{\infty} \frac{e^{-u}}{u}$ du from $x=20$ to $x=50$, Scientific Papers of the Institute of Physical and Chemical Research, Tokyo, Table No. 3, June, 1929, pp. 181-215.

8. Smith, T., Diffusion of Cerium and Zirconium in Molten Uranium, J. Electrochem. Soc. 106 1046-5l (1959).

9. Argonne National Laboratory Internal Memorandum from Maurer, D., to Hummel, H., A Table of Integrals Involving the Error Function and Related Functions (August 21, 1958).

10. Kelley, K. K. Contributions to the Data on Theoretical Metallurgy, Bulletin 584, Bureau of Mines (1960), p.200.

11. Smithells, C. J., Metals Reference Book, 2nd.Ed., Interscience Publishers., N.Y.(1955), p. 548.

12. Carslaw, H.S., and Jaeger, J.C., Conduction of Heat in Solids, 2nd Ed., Oxford, Clarendon Press (1959).

\section{ACKNOW LEDGMENT}

Appreciation is expressed to C. E. Dickerman of Argonne National Laboratory for suggestions that contributed strongly to the practical value of this report. 